\title{
An assessment of macrophysical and microphysical cloud properties driving radiative forcing of shallow trade-wind clouds
}

\author{
Anna E. Luebke ${ }^{1}$, André Ehrlich ${ }^{1}$, Michael Schäfer ${ }^{1}$, Kevin Wolf $^{1, a}$, and Manfred Wendisch ${ }^{1}$ \\ ${ }^{1}$ Leipzig Institute for Meteorology, University of Leipzig, Leipzig, Germany \\ ${ }^{a}$ now at: Institut Pierre-Simon Laplace, Sorbonne Université, Paris, France
}

Correspondence: Anna E. Luebke (anna.luebke@uni-leipzig.de)

Received: 28 September 2021 - Discussion started: 15 October 2021

Revised: 27 January 2022 - Accepted: 31 January 2022 - Published: 1 March 2022

\begin{abstract}
The clouds in the Atlantic trade-wind region are known to have an important impact on the global climate system. Acquiring a comprehensive characterization of these clouds based on observations is a challenge, but it is necessary for the evaluation of their representation in models. An exploration of how the macrophysical and microphysical cloud properties and organization of the cloud field impact the large-scale cloud radiative forcing is presented here. In situ measurements of the cloud radiative effects based on the Broadband AirCrAft RaDiometer Instrumentation (BACARDI) on board the High Altitude and LOng Range Research Aircraft (HALO) and cloud observations from the GOES-16 satellite collected during the ElUcidating the RolE of Cloud-Circulation Coupling in ClimAte (EUREC $\left.{ }^{4} \mathrm{~A}\right)$ campaign demonstrate what drives the cloud radiative effects in shallow trade-wind clouds. We find that the solar and terrestrial radiative effects of these clouds are largely driven by their macrophysical properties (cloud fraction and a scene-averaged liquid water path). We also conclude that the microphysical properties, cloud top height and organization of the cloud field increasingly determine the cloud radiative effects as the cloud fraction increases.
\end{abstract}

1

Shallow, marine trade-wind cumuli in the tropics have been established as key components in influencing the radiative energy budget of the Earth's atmosphere in response to a changing climate (Bony et al., 2017; Klein et al., 2017; Stevens et al., 2021). Through various research efforts, the microphysical, macrophysical and radiative properties of these clouds have been mapped out, for example, with the aid of high-resolution satellite observations (Zhao and Di Girolamo, 2007; Mieslinger et al., 2019) and through dedicated research campaigns such as Cloud, Aerosol, Radiation and tuRbulence in the trade regime over Barbados (CARRIBA; Siebert et al., 2013) and the Next-Generation Aircraft Remote Sensing for Validation field studies (NARVAL I and NARVAL II; Stevens et al., 2019). Such observational data sets are ideal for the purposes of process studies and the validation and improvement of numerical weather prediction models (NWPs) and global climate models (GCMs). However, constraining a comprehensive characterization of shallow trade-wind clouds based on their macrophysical and microphysical properties and assessing the associated dynamics remain difficult. An often cited reason for this is the lack of representative observations (e.g., Zhang et al., 2013; Herwehe et al., 2014; Khain et al., 2015; Bony et al., 2017). Specifically, though model studies are able to quantify the radiative budget, it is challenging to obtain the suitable microphysical and radiative measurements for verification. Thus, the impact of shallow trade-wind clouds on the atmospheric radiative energy budget in a warming world remains a critical topic.

Despite this challenge, the influence of cloud properties on their radiative effects is already well known. For solar (shortwave) radiative effects, cloud fraction has been established as a useful parameter for estimating the radiative properties or effects of the clouds for a given scene (e.g., 
Chen et al., 2000), particularly by using the relation between albedo, which is the combination of cloudy- and cloud-freesky albedo, and cloud fraction (George and Wood, 2010; Bender et al., 2011, 2016; Engström et al., 2015). However, this relation can be further influenced by variations in liquid water path (LWP) when cloud fraction is held constant (Bender et al., 2016). Cloud microphysical characteristics have been found to have less of an impact, but George and Wood (2010) suggest that these impacts may be masked by the complex interactions between macrophysical and meteorological variability. Assessments of the cloud albedo demonstrate how changes in aerosol concentrations (Peng et al., 2002; Diamond et al., 2020) and thus droplet size via the Twomey effect (Twomey, 1977; Werner et al., 2014) enhance cloud albedo and cloud optical thickness due to a decrease in droplet effective radius $\left(r_{\text {eff }}\right)$. However, this relation between $r_{\text {eff }}$ and cloud albedo differs between optically thick and thin clouds (Lohmann et al., 2000), likely stemming from a dependence on whether the cloud is precipitating, which impacts LWP and the droplet size distribution. In optically thick clouds, cloud albedo increases with decreasing $r_{\text {eff }}$, while cloud albedo decreases with decreasing $r_{\text {eff }}$ in optically thin clouds. The spatial distribution or organization of the cloud field, which is strongly related to cloud fraction and LWP, also impacts the resulting albedo (Wood and Hartmann, 2006; McCoy et al., 2017).

With regard to terrestrial (longwave) cloud radiative effects, macrophysical properties are known to have the greatest influence. Cloud top height (or temperature) has been found to have the most impact, but cloud amount is also important (Ardanuy et al., 1988; Chen et al., 2000). As described by Chen et al. (2000), because cloud top height is so critical to terrestrial cloud radiative effects, the cloud type is also known be an important factor. Among shallow clouds, stratocumulus along with stratus and altostratus have the greatest impact on surface terrestrial effects. The organization of the cloud field also plays a role. For example, Tobin et al. (2012) found that the outgoing terrestrial radiation of deep convective clouds decreased as the cloud field became more aggregated. Whether this holds true for shallow tradewind clouds is explored in this study.

Thus far, observational research in this area has largely relied on satellite-based measurements of the cloud radiative effects, which has the benefit of providing long-term, global observations but often with the trade-off of a coarser spatial and temporal resolution. Furthermore, the radiative flux densities are usually derived from combinations of radiance observations and radiative transfer models or the Clouds and the Earth's Radiant Energy System (CERES) instruments. Thus, in these cases, irradiance is not measured directly, and uncertainties are introduced due to the assumptions made in the calculations of irradiance. However, the recent ElUcidating the RolE of Cloud-Circulation Coupling in ClimAte (EUREC ${ }^{4} \mathrm{~A}$ ) campaign in 2020 used multiple platforms (e.g., airborne and satellite) and instrumentation methods to assess the cloud field from multiple angles, both literally and with regard to research topics, and with a strong degree of collocation (Stevens et al., 2021). Among these measurements are in situ airborne observations of solar and terrestrial broadband irradiance by broadband radiometers, which directly measure irradiance without the constraints of satellite-based measurements.

With these new radiation observations, the major objective of this study is to understand how and to what degree the macrophysical and microphysical cloud properties influence the cloud radiative effects of shallow trade-wind clouds. Furthermore, we seek to understand their relative importance in driving the cloud radiative effects and how different properties might work together or against each other to result in a specific cloud radiative effect. In Sect. 2, the relevant instrumentation, data products, and analysis methods for this study are discussed. The results of the analysis are presented in Sect. 3 with different approaches to exploring the data and the relations between the cloud properties and the solar and terrestrial cloud radiative effects. Section 4 concludes by summarizing and discussing the results and their implications as well as providing the context for future work.

\section{Methodology}

The analysis presented here is based on data taken during the EUREC ${ }^{4}$ A campaign (Bony et al., 2017; Stevens et al., 2021), which took place in the winter of 2020. During this season, the trade-wind region is characterized by more cloud cover and stratiform structures in comparison to the rather convective, wet summer season (Nuijens et al., 2014). The general aim of this campaign was to sample the clouds and large-scale dynamics in the trade-wind region of the Atlantic Ocean just off the coast of Barbados. With the participation of four research vessels, five aircraft, three remote sensing stations on Barbados and many unmanned research crafts, the synergistic approach of this campaign offered the opportunity to observe the trade-wind region from several perspectives. Specifically, data from the High Altitude and LOng Range Research Aircraft (HALO) operated by the DLR (Deutsches Zentrum für Luft- und Raumfahrt, e.V.) and the Geostationary Operational Environmental Satellite 16 (GOES-16) operated by the National Oceanic and Atmospheric Administration (NOAA) are utilized in this study.

\subsection{Airborne observations using HALO}

As in NARVAL I and NARVAL II, which previously took place in this region, an instrument payload known as the cloud-observatory configuration was installed on HALO (Stevens et al., 2019). This payload consists primarily of remote sensing instruments comparable to the instrumentation of the current A-Train satellite constellation and the upcoming Earth Cloud Aerosol and Radiation Explorer (EarthCARE) satellite. For EUREC ${ }^{4} \mathrm{~A}$, the instrumentation was 
extended with the Broadband AirCrAft RaDiometer Instrumentation (BACARDI; Konow et al., 2021) and the Video airbornE Longwave Observations within siX channels (VELOX; Schäfer et al., 2021) system. This instrument payload was designed to observe the cloud population as well as the surrounding environment (i.e., dynamic and thermodynamic conditions) simultaneously. Active and passive sensors provide a characterization of the cloud properties - microphysical, macrophysical and radiative - in vertical and horizontal dimensions, while methodically released dropsondes along the flight path obtain in situ measurements of the vertical atmospheric profile. See Konow et al. (2021) for further information concerning the instrumentation and flights of HALO during EUREC ${ }^{4} \mathrm{~A}$.

For the purposes of the campaign, specifically as a strategy for properly capturing the scale of the dynamics influencing cloud development, HALO primarily flew in a pattern defined by clockwise circles repeated in the same location for most flights (centered at $13.3^{\circ} \mathrm{N}, 57.717^{\circ} \mathrm{W}$ ), approximately $220 \mathrm{~km}$ in diameter and requiring an hour to complete. As the synoptic situation is largely stable in this region with regularly occurring clouds (Bony et al., 2017), the chosen flight strategy for the campaign was independent of the meteorological situation and instead focused on achieving flights at different times of day to fully capture the diurnal cycle in the region (Vial et al., 2019; Konow et al., 2021). Other flight patterns were also observed for additional purposes, but the work here focuses on the circles so as to capture and constrain the observations used in this analysis to a single location.

The radiative component of this analysis is estimated from observations from BACARDI (Konow et al., 2021). This new radiometer package comprises two sets of Kipp and Zonen pyranometers (CMP22) and pyrgeometers (CGR4) mounted to the aircraft fuselage. Together, they provide measurements of the upward and downward solar (sensitive to wavelengths between 0.2 and $3.6 \mu \mathrm{m})$ and terrestrial $(4.5-42 \mu \mathrm{m})$ broadband irradiance at flight level. The respective uncertainties of the measurements from these sensors are $1 \%$ and $4 \%$, which are calculated during calibration procedures before and after the campaign (Kipp and Zonen B.V, 2014, 2016). The data used here have been corrected in post-processing for temperature dependence and response time of the sensors as well as aircraft attitude, similarly to the methods described by Ehrlich and Wendisch (2015).

\subsection{Satellite observations from GOES-16}

The cloud properties in this analysis come from the data products of the GOES-16 geostationary satellite Advanced Baseline Imager (ABI) (Schmit et al., 2017, 2018). GOES16 is part of the GOES-R series of satellites. Throughout the duration of the campaign, GOES-16 was operated to produce images of the EUREC ${ }^{4} A$ research domain at a temporal resolution of $1 \mathrm{~min}$, when possible, which turns out to be a strong benefit for analyzing the evolution of the clouds. Specifically, we utilize the cloud mask product (Heidinger and Straka, 2012) as well as retrieved LWP, $r_{\text {eff }}$ (Walther et al., 2013) and cloud top height $\left(z_{\mathrm{ct}}\right.$; Heidinger, 2012) products. The spatial resolution for the data products used here is $2 \mathrm{~km} \times 2 \mathrm{~km}$ at nadir. The cloud mask shows good agreement with the Cloud-Aerosol Lidar and Infrared Pathfinder Satellite Observation (CALIPSO) over the contiguous United States, but low clouds (cloud tops below $2 \mathrm{~km}$ ) were the most commonly missed cloud type (Jiménez, 2020). Also, further evaluation shows that the increased pixel resolution relative to its predecessor, GOES-13, results in an improved $r_{\text {eff }}$ retrieval when compared to airborne measurements (Painemal et al., 2021). It is therefore expected that the LWP retrieval is also improved; however, both products continue to have a high bias.

For the application of the cloud mask product from GOES16 , pixels labeled as "probably cloudy" and "cloudy" are accepted as cloud pixels in the calculation of the cloud fraction. The cloud mask is also used to calculate the organization of the cloud field, which is described by the organization index, $I_{\text {org }}$ (Weger et al., 1992; Tompkins and Semie, 2017). This index classifies a given cloud scene as regular, random, or clustered. The classification is based on statistics of the nearest neighbor (NN) distances between clouds in comparison to a theoretical scene with a random distribution, which can be described as a Poisson point process. If the NN distances are on average larger than they would be if the clouds were randomly distributed $\left(I_{\text {org }}<0.5\right)$, then the scene is regular. If they are smaller $\left(I_{\text {org }}>0.5\right)$, the scene is classified as clustered. An $I_{\text {org }}$ value of 0.5 indicates that the scene is random. More detailed explanations can be found in Tompkins and Semie (2017) and Mieslinger et al. (2019).

\subsection{Deriving cloud radiative effects}

Cloud radiative forcing $(\Delta F)$ is defined as the difference between the observed net (downward - upward) irradiance $\left(F^{\downarrow}-F^{\uparrow}\right)$ at an altitude ( $z$, in this case flight altitude) and the net irradiance in cloud-free conditions, as shown in Eq. (1) (Stapf et al., 2021):

$$
\begin{aligned}
\Delta F(z) & =\left[F^{\downarrow}(z)-F^{\uparrow}(z)\right]_{\text {cloud }} \\
& -\left[F^{\downarrow}(z)-F^{\uparrow}(z)\right]_{\text {cloud-free }}
\end{aligned}
$$

$\Delta F$ can also be further divided into its terrestrial $\left(\Delta F_{\text {ter }}\right)$ and solar $\left(\Delta F_{\text {sol }}\right)$ components, which are defined in Eqs. (2) and (3), respectively:

$$
\begin{aligned}
\Delta F_{\text {ter }}(z)= & {\left[F_{\text {ter }}^{\downarrow}(z)-F_{\text {ter }}^{\uparrow}(z)\right]_{\text {cloud }} } \\
& -\left[F_{\text {ter }}^{\downarrow}(z)-F_{\text {ter }}^{\uparrow}(z)\right]_{\text {cloud-free }}, \\
\Delta F_{\text {sol }}(z)= & {\left[F_{\text {sol }}^{\downarrow}(z)-F_{\text {sol }}^{\uparrow}(z)\right]_{\text {cloud }} } \\
& -\left[F_{\text {sol }}^{\downarrow}(z)-F_{\text {sol }}^{\uparrow}(z)\right]_{\text {cloud-free }}
\end{aligned}
$$


For $\Delta F_{\text {sol }}$, Eq. (3) can be further simplified with the assumption that $F_{\text {sol }}^{\downarrow}$ is identical in cloudy and cloud-free cases while flying above cloud:

$\Delta F_{\text {sol }}(z)=-\left[F_{\text {sol,cloud }}^{\uparrow}(z)\right]-\left[-F_{\text {sol,cloud-free }}^{\uparrow}(z)\right]$.

However, $\Delta F_{\text {sol }}$ is a function of solar zenith angle (SZA). For this reason, albedo (Eq. 5) is a more useful parameter to describe solar radiative fluxes because it expresses the relative difference between $F_{\text {sol }}^{\downarrow}$ and $F_{\text {sol }}^{\uparrow}$, thereby avoiding the SZA dependence:

$\alpha=\frac{F_{\text {sol }}^{\uparrow}}{F_{\text {sol }}^{\downarrow}}$.

With this in mind, the dependence of $\Delta F_{\text {sol }}$ on SZA can also be addressed. The same strategy applied to Eq. (3), wherein the cloud-free fluxes are subtracted from the total to isolate the cloud effect, can also be used with albedo (Eq. 5) to isolate the cloud effect on the observed albedo $\left(\alpha_{\mathrm{ce}}\right)$. Simply, the cloudy and cloud-free $F_{\text {sol }}^{\uparrow}$ in Eq. (4) are normalized with $F_{\text {sol }}^{\downarrow}$, which removes the SZA dependence, thus making observations from different SZAs comparable:

$\alpha_{\mathrm{ce}}(z)=-\left[\frac{F_{\mathrm{sol}, \mathrm{cloud}}^{\uparrow}(z)}{F_{\mathrm{sol}}^{\downarrow}(z)}\right]-\left[-\frac{F_{\text {sol,cloud-free }}^{\uparrow}(z)}{F_{\mathrm{sol}}^{\downarrow}(z)}\right]$.

Since measurements in cloud-free conditions cannot be obtained simultaneously or in similar conditions to those observed during each flight, simulated cloud-free cases of each flight are calculated using the libRadtran software package (Emde et al., 2016). Dropsondes along the flight track provide measured profiles of thermodynamic atmospheric properties (humidity, temperature) used in the simulations (George et al., 2021). Estimations of the uncertainties of these simulations are given in Table 1. The largest source of uncertainty is found to be the atmospheric data, particularly for the cloud-free $F_{\text {ter }}^{\uparrow}$. Due to the limited spatial resolution of the dropsondes, this method cannot always replicate an observed cloud-free situation. Additionally, because the sondes may pass through clouds on their way down, the humidity and temperature profiles used for the simulation could be biased. In order to minimize these effects, only the simulations at the dropsonde locations are used to approximate a cloudfree $F_{\text {ter }}^{\uparrow}$, which is then interpolated for the rest of the flight track. It should also be noted that aerosol particle properties were not included in the simulations, as their effect is anticipated to be minimal relative to clouds, but their influence may still be included in the cloud effects calculated here.

\subsection{Combining satellite and aircraft observations}

In the case of the analysis presented here, only a subset of seven flights is used, which are described in Table 2. Those times when data from both BACARDI and GOES-16 were available are given there. Unfortunately, this also means that only partial flights are usable in some cases. Additional filters were applied regarding the SZA and the presence of clouds above the aircraft (e.g., cirrus). To prevent complications in the case of low Sun conditions and to avoid the need to consider cirrus in this study, the data were limited to SZAs less than $70^{\circ}$ and to flights with cloud-free conditions above the flight altitude of HALO. Furthermore, the maximum mean $z_{\mathrm{ct}}$ for an observed scene is limited to $4 \mathrm{~km}$ to avoid the inclusion of deeper convective clouds, which have properties and associated relationships that should be considered separately. Scenes without clouds below HALO are also excluded.

To enable the combined use of BACARDI and GOES-16 data, spatial collocation needs to be assured, with both observations covering the same footprint at the same time. BACARDI has a $180^{\circ}$ field of view (FOV), but radiation from different directions is weighted with the viewing zenith angle. Based on geometry, $95 \%$ of the upward irradiance is determined by radiances within a FOV of approximately $154^{\circ}$. However, such a footprint may not necessarily be compatible with the radiation measured by GOES-16. A quality check was performed to ensure the compatibility of BACARDI and GOES-16, and it was found that a BACARDI footprint corresponding to a FOV of $102^{\circ}$ is appropriate to use with observations from GOES-16. At a typical flight altitude of $10 \mathrm{~km}$, a FOV of $102^{\circ}$ corresponds to a footprint with a radius of approximately $13 \mathrm{~km}$. This quality check is described in more detail in Appendix A.

Additionally, the cloud scenes observed over the course of each minute are oblong instead of perfectly circular due to the movement of the aircraft. Over the course of a minute, the aircraft travels approximately $12 \mathrm{~km}$ with an average ground speed of $200 \mathrm{~m} \mathrm{~s}^{-1}$, so the area of each 1 min scene is approximately $820 \mathrm{~km}^{2}$. Examples of the GOES-16 cloud mask product and the corresponding footprint cutout from the flight on 24 January 2020 are shown in Fig. 1.

Mean values are used to describe the cloud properties of each scene. The individual quantities are weighted with the cosine of the viewing angle across the footprint of BACARDI before calculating a mean value. This strategy is used to capture an expression of the properties that is compatible with the radiative view that BACARDI has (i.e., clouds on the periphery make less of an impact than clouds in the nadir view of the instrument). Furthermore, two representations of the LWP are used - mean LWP calculated for the cloud pixels only $\left(\mathrm{LWP}_{\text {cloud }}\right)$ and a mean LWP calculation that includes both the cloudy and cloud-free pixels within the footprintsized cloud scene $\left(\mathrm{LWP}_{\text {scene }}\right)$. $\mathrm{LWP}_{\text {scene }}$ considers LWP in a more macrophysical sense because of its relationship with cloud fraction and the fact that it represents the amount of water distributed over the scene, while $\mathrm{LWP}_{\text {cloud }}$ considers LWP to be microphysical in nature.

The size of the footprint cut out from the full GOES scene is not sufficient for a meaningful quantification of the cloud organization. Trade-wind cumuli typically have sizes (mea- 
Table 1. Estimations of the uncertainty of the simulated cloud-free conditions based on different possible sources.

\begin{tabular}{lllr}
\hline Source of uncertainty & Wavelength range & Parameter & Uncertainty \\
\hline Atmospheric profile (dropsonde) & Solar & $F^{\downarrow}$ & $<1 \%$ \\
& & $F^{\uparrow}$ & $3 \%$ \\
& Terrestrial & $F^{\downarrow}$ & $6 \%$ \\
Surface temperature ( $\pm 3 \mathrm{~K})$ & & $F^{\uparrow}$ & $8 \%$ \\
& & $F^{\downarrow}$ & $<1 \%$ \\
& & $F^{\uparrow}$ & $2.5 \%$ \\
\hline
\end{tabular}

Table 2. The flights from EUREC ${ }^{4} \mathrm{~A}$ that are used in this analysis are given here with their respective flight IDs (HALO-mmdd) along with the times when HALO was in the circling flight pattern and GOES-16 data were available. The amounts of time and number of GOES images are for cloudy and cloud-free sky, but the total amount of time and number of GOES images for cloudy sky only are given as well. The general descriptions of the flights come from notes in the flight reports.

\begin{tabular}{|c|c|c|c|c|}
\hline Flight ID & Time (UTC) & Duration (hh:mm) & GOES images & General description \\
\hline HALO-0124 & $11: 52-16: 56$ & 5:05 & 305 & Shallow $\mathrm{Cu}, \mathrm{Sc}$, deeper convection \\
\hline HALO-0128 & $15: 18-18: 38 ; 19: 53-20: 21$ & 3:40 & 220 & Shallow $\mathrm{Cu}$ clusters and lines \\
\hline HALO-0131 & $15: 28-18: 50 ; 19: 56-20: 23$ & $3: 51$ & 231 & Dust, suppressed shallow $\mathrm{Cu}$, "fish" clusters, Sc \\
\hline HALO-0202 & $18: 29-19: 34$ & 1:06 & 66 & Large "flowers", some dissipating \\
\hline HALO-0207 & $15: 00-15: 34 ; 17: 14-20: 23$ & $3: 45$ & 225 & Shallow $\mathrm{Cu}$, "flowers", precipitation \\
\hline HALO-0209 & $11: 47-12: 56 ; 13: 54-17: 24$ & $4: 41$ & 281 & Shallow and deeper $\mathrm{Cu}$, cold pools, precipitation \\
\hline \multirow[t]{3}{*}{ HALO-0211 } & $12: 57-18: 55$ & $5: 58$ & 358 & Convection with precipitation, $\mathrm{Sc}$, shallow $\mathrm{Cu}$ \\
\hline & Total & 28:06 & 1686 & \\
\hline & Total (cloudy scenes only) & $14: 02$ & 842 & \\
\hline
\end{tabular}

sured as maximum diameter) from a few hundred meters to less than $2 \mathrm{~km}$ (Schnitt et al., 2017), so only a few clouds are present within the GOES cutouts. However, assuming that the cloud organization is driven on larger scales, we used a larger domain size of $5^{\circ} \times 5^{\circ}$ for this assessment of organization. Given the coarse resolution of GOES-16, this consideration seems appropriate. The full example scenes in Fig. 1 are the larger domain size, but for the analysis, the center of each larger domain would be aligned with the location of HALO at that time.

\section{Sensitivity of cloud radiative effects to cloud properties}

\subsection{Overview of cloud data}

The radiative data in this study were recorded by the BACARDI instrument, and the cloud properties were obtained from GOES-16 satellite data products (see Sects. 2.1 and 2.2). A set of histograms depicting the distributions of the data is given in Fig. 2. The mean $\alpha_{\text {ce }}$ is 0.086 , while the mean $\Delta F_{\text {ter }}$ is $6.35 \mathrm{~W} \mathrm{~m}^{-1}$. The mean $\Delta F_{\text {sol }}$ is $-77.64 \mathrm{~W} \mathrm{~m}^{-1}$, which demonstrates that the solar part of the cloud radiative forcing of shallow trade-wind cumuli is significantly stronger than the forcing from the terrestrial part. However, due to the influence of SZA on $\Delta F_{\text {sol }}$, the mean value is provided only as an estimate for the purposes of comparison. The mean cosine-weighted cloud fraction is 0.204 , which is larger than the value of 0.087 reported by Mieslinger et al. (2019) from Advanced Spaceborne Thermal Emission and Reflection Radiometer (ASTER) imagery of trade-wind cumuli. Differences are likely to stem from the exclusion of non-cloudy scenes in this study as well as the small footprint and coarseness of the GOES satellite resolution. The mean $z_{\mathrm{ct}}$ of $1.9 \mathrm{~km}$ found here is slightly higher than the $1.3 \mathrm{~km}$ reported in their study, and the cloud field is found to be less clustered on average ( $I_{\text {org }}$ of 0.74 versus 0.89 ). The overall observed values are within similar ranges, so the smaller sample size within a single season may also be the cause of differences from previous studies. The mean $\mathrm{LWP}_{\text {scene }}$ and mean $\mathrm{LWP}_{\text {cloud }}$ are 19 and $98 \mathrm{~g} \mathrm{~m}^{-2}$, respectively. For comparison, during the NARVAL campaigns, retrievals of LWP from remote sensing instrumentation reported a mean LWP from the sampled clouds of about $63 \mathrm{~g} \mathrm{~m}^{-2}$ during the dry, winter season (Jacob et al., 2019). The fact that thicker clouds (LWP $>50 \mathrm{~g} \mathrm{~m}^{-2}$ ) were also more frequent during this season was also noted. Mean $r_{\text {eff }}$ in this study is $16 \mu \mathrm{m}$, which is comparable to previous observations in the vicinity of Barbados $(10-17 \mu \mathrm{m}$ in pristine cases; Werner et al., 2014). 

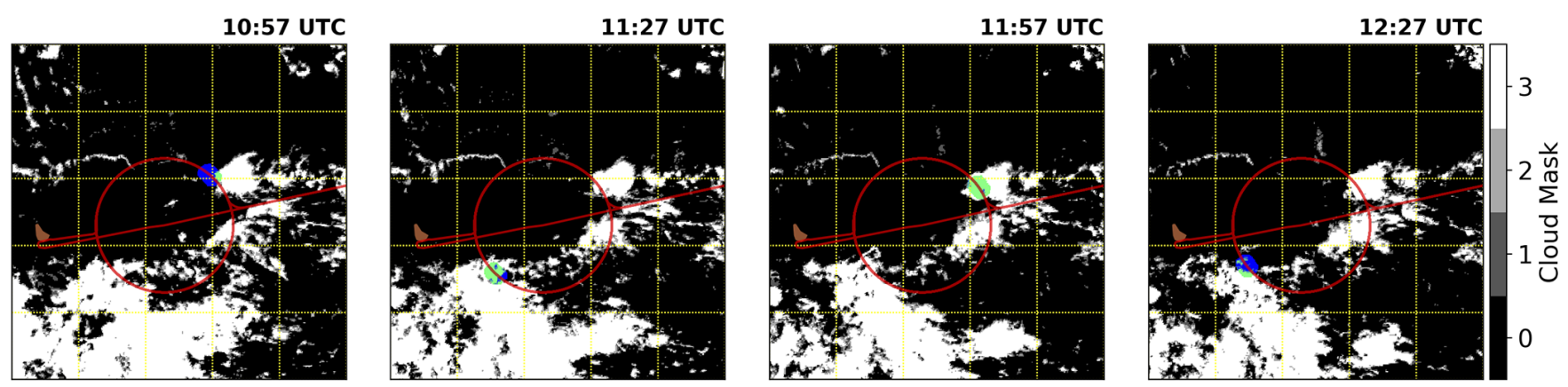

Figure 1. Four example scenes from the flight on 24 January 2020. The cloud mask product from GOES is displayed, with the blue (cloudfree) and green (cloud) colors indicating the collocated $102^{\circ}$ footprint of BACARDI. The solid red line indicates the flight track. The island of Barbados is shown in brown for reference.

\subsection{Observed relations between cloud properties and cloud radiative effects}

The impact of cloud properties on the radiation budget was analyzed separately for the solar and terrestrial components of the observed radiation because these two components are known to interact differently with cloud properties. A series of scatter plots in Figs. 3 and 4 demonstrates the relationships of $\alpha_{\mathrm{ce}}$ and $\Delta F_{\mathrm{ter}}$, respectively, with the various cloud properties analyzed here.

In Fig. 3, it becomes apparent that the macrophysical properties (cloud fraction and $\mathrm{LWP}_{\text {scene }}$ ) demonstrate the most obvious relationship with $\alpha_{\mathrm{ce}}-$ as $\alpha_{\mathrm{ce}}$ increases, the cloud fraction and $\mathrm{LWP}_{\text {scene, }}$, panels (a) and (b), also increase, as expected. The relation between $\alpha_{\mathrm{ce}}$ and $z_{\mathrm{ct}}$ (Fig. 3f) is more weakly correlated, but generally as $z_{\mathrm{ct}}$ increases, so does $\alpha_{\mathrm{ce}}$. In the case of LWP cloud (Fig. 3c), two populations emerge - one where LWP and $\alpha_{\mathrm{ce}}$ are strongly positively correlated and one where an increase in LWP does not appear to impact $\alpha_{\text {ce }}$. This second branch may represent cases where changes in microphysical properties are less relevant to the radiative impact of the clouds. From the perspective of a scatter plot, the relationships of $\alpha_{\mathrm{ce}}$ with $r_{\mathrm{eff}}$ and $I_{\mathrm{org}}$ are unclear given the very weak correlations (Fig. $3 \mathrm{~d}$ and e).

Based on these results, we would expect to see the same patterns to be observed for individual flights as well. The different colored points and bars in Fig. 3 depict the median values (see also Table 3) of each parameter for each of the seven investigated flights and the range from the 10th to 90th percentiles of the different distributions, respectively. The clouds observed during the flight on 28 January 2020 (red star) have the lowest $\alpha_{\text {ce }}$, while the highest median $\alpha_{\text {ce }}$ was observed during the flight on 24 January (black circle). The expectation that follows is that the cloud properties will also display a pattern according to their relationship with $\alpha_{\mathrm{ce}}$. For example, properties like cloud fraction and $\mathrm{LWP}_{\text {scene }}$ are also generally increasing in a similar flight order to $\alpha_{\mathrm{ce}}$, with 28 and 31 January showing some of the lowest cloud fraction

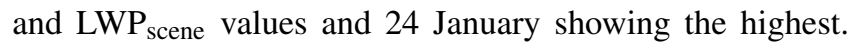
However, the observations on 7 February (green plus) do not follow this trend for both cloud fraction and LWP. The remaining properties $\left(\mathrm{LWP}_{\text {cloud }}, r_{\mathrm{eff}}, I_{\mathrm{org}}\right.$, and $\left.z_{\mathrm{ct}}\right)$ appear not to follow any pattern given the order of the flights with increasing $\alpha_{\mathrm{ce}}$. This demonstrates again that the macrophysical properties are more closely linked to the observed $\alpha_{\mathrm{ce}}$ than the microphysical properties.

From this series of panels in Fig. 3, it is also possible to pick out details about each flight and identify relationships between cloud properties and $\alpha_{\mathrm{ce}}$. For example, the $\alpha_{\mathrm{ce}}$ values measured during the flight on 31 January (orange triangle) fall on the relatively lower end of observed $\alpha_{\mathrm{ce}}$ as well as similarly low cloud fraction and $\mathrm{LWP}_{\text {scene. The mean }}$ LWP $_{\text {cloud }}$ is relatively high and the $r_{\text {eff }}$ relatively low. On this day, the cloud field was characterized as quite clustered with lower cloud tops. During this flight, the cloud field was populated with suppressed shallow cumulus, so-called "fish" structures (Schulz et al., 2021), and lots of dust. The dust could be an explanation of why the $r_{\text {eff }}$ is quite small, and the notion of suppressed shallow cumulus fits the lower cloud top heights, but confirmation of this assertion would require further information and analysis. While small droplets typically indicate higher $\alpha_{\mathrm{ce}}$, the characteristics of the macrophysical properties seem to be more dominant in this case. In contrast, the flight on 7 February (green plus) has a lower $\alpha_{\text {ce }}$ relative to other flights but has a higher cloud fraction and $\mathrm{LWP}_{\text {scene. The }} \mathrm{LWP}_{\text {cloud }}$ is also relatively lower, the $r_{\text {eff }}$ is relatively larger, the cloud tops are higher and the cloud field is less clustered than most flights. This flight was dominated by cloud structures known as "flowers" (Schulz et al., 2021), and precipitation was noted. Thus, it could be possible that, despite the higher cloud fraction and therefore higher amount of liquid water distributed in the scene, which can be attributed to the large "flower" clouds, the clouds themselves had a lower LWP and droplets with a higher $r_{\text {eff. This }}$ could demonstrate a case wherein the macrophysical and microphysical properties counteract each other and raise new questions to be answered. For example, does this always happen, or are there specific requirements for this? In the case of the 31 January flight, do the microphysical properties make 

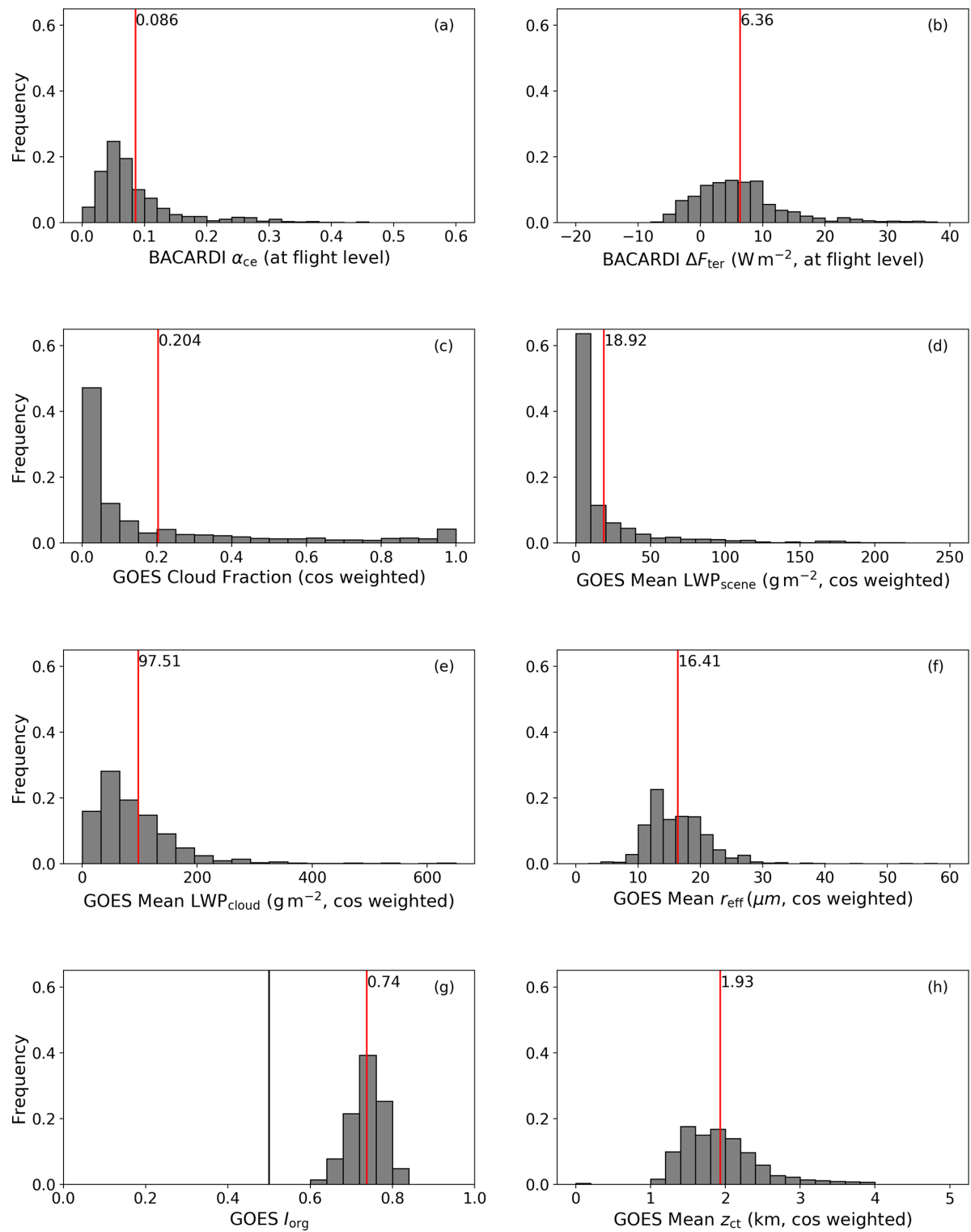

Figure 2. Histograms of all cloud properties for the subset of EUREC ${ }^{4} \mathrm{~A}$ flights and data used in the analysis. Labeled red bars indicate the mean value. (a) Effect of clouds on albedo. (b) Terrestrial cloud radiative forcing. (c) Cloud fraction. (d) Mean liquid water path for the scene. (e) Mean liquid water path for the clouds. (f) Mean effective radius. (g) Organization index; black bar at 0.5 separates normal and

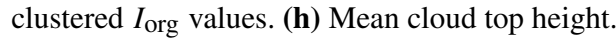

Table 3. Median values shown in Figs. 3 and 4. The highest and lowest values for each parameter are marked in italics.

\begin{tabular}{lrrrrrrr}
\hline & 24 Jan & 28 Jan & 31 Jan & 02 Feb & 07 Feb & 09 Feb & 11 Feb \\
\hline$\alpha_{\text {ce }}$ & 0.091 & 0.046 & 0.055 & 0.087 & 0.048 & 0.064 & 0.066 \\
$\Delta F_{\text {ter }}\left(\mathrm{W} \mathrm{m}^{-1}\right)$ & 6.38 & 3.73 & 2.89 & -0.81 & 5.36 & 1.94 & 9.47 \\
Cloud fraction & 0.261 & 0.027 & 0.023 & 0.075 & 0.096 & 0.028 & 0.045 \\
$\mathrm{LWP}_{\text {scene }}\left(\mathrm{g} \mathrm{m}^{-2}\right)$ & 15.34 & 2.19 & 2.44 & 2.24 & 7.39 & 1.92 & 4.32 \\
$\mathrm{LWP}_{\text {cloud }}\left(\mathrm{g} \mathrm{m}^{-2}\right)$ & 69.73 & 106.43 & 90.63 & 77.77 & 76.81 & 62.82 & 67.64 \\
$r_{\text {eff }}(\mu \mathrm{m})$ & 19.68 & 14.06 & 12.02 & 12.22 & 19.03 & 13.26 & 13.18 \\
$I_{\text {org }}$ & 0.74 & 0.76 & 0.79 & 0.78 & 0.72 & 0.76 & 0.69 \\
$z_{\text {ct }}(\mathrm{km})$ & 1.87 & 1.43 & 1.60 & 1.91 & 2.00 & 2.13 & 1.68 \\
\hline
\end{tabular}



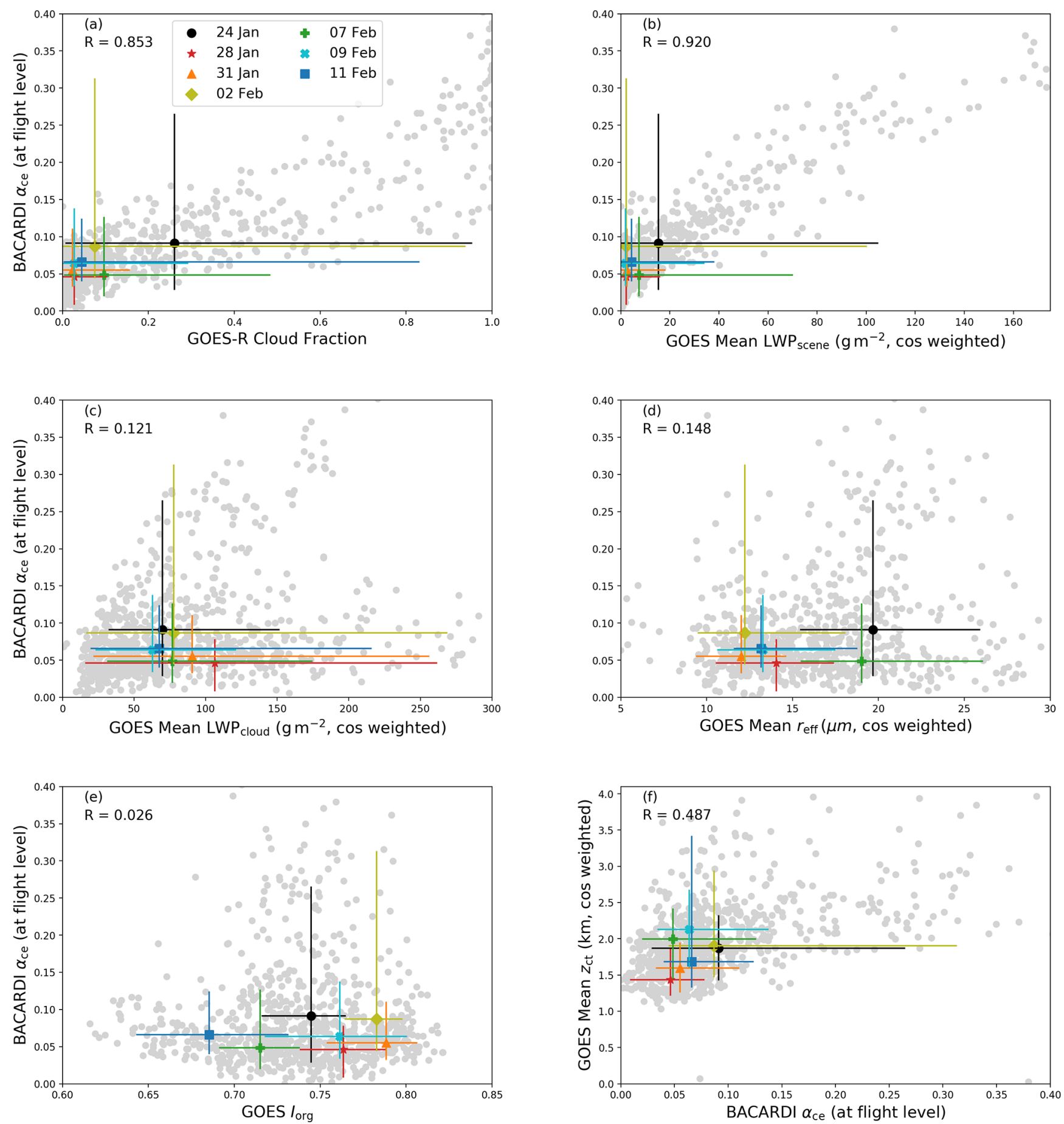

Figure 3. (a-f) Scatter plots (gray) of different cloud properties as a function of $\alpha_{\mathrm{ce}}$ for the subset of EUREC ${ }^{4}$ A flights used in the analysis. Different colored shapes denote the median observed values from individual flights, while the associated bars indicate the range of values between the 10th and 90th percentiles. Plots are zoomed in to include at least the 10th-90th percentile ranges for each variable.

a contribution to $\alpha_{\mathrm{ce}}$ at all? If, for example, the $r_{\mathrm{eff}}$ had been larger, would the $\alpha_{\mathrm{ce}}$ have been noticeably lower?

Another feature of the measurements collected on 7 February that is worth noting in Fig. 3 is that the percentile line for cloud fraction reveals that a relatively large range of cloud fractions was sampled throughout the flight. This is true also for the flights on 24 January, 2 February and 11 February. The implication here is that a more diverse range of clouds and/or dynamic situations was encountered and sampled in a single flight, unlike 31 January, for example. Therefore, Fig. 3 may 
be an incomplete picture, as the inclusion of multiple cloud situations in this statistical view could certainly make the interpretation more difficult.

The terrestrial component of the cloud radiative effect has a different relationship with the same cloud properties. Figure 4 contains a series of scatter plots showing the general relationship of different cloud properties with the $\Delta F_{\text {ter }}$ calculated using Eq. (1). The majority of the calculated $\Delta F_{\text {ter }}$ values are positive, indicating a weak warming effect above the clouds, with some indication of weak cooling for the lowest clouds (below $2.5 \mathrm{~km}$ ). This weak warming is typical of low-level clouds given the low temperature contrast with the warm surface (Chen et al., 2000). The cooling, however, might fit into the uncertainties of the observations and simulations, as mentioned in Sect. 2.3. Similarly to $\alpha_{\mathrm{ce}}$, the cloud fraction (Fig. 4a) appears to be strongly tied to the resulting $\Delta F_{\text {ter }}$. The relationship with $z_{\text {ct }}$ also appears more pronounced, showing that $z_{\mathrm{ct}}$ is linked to a decrease in cloud top temperature, as expected (Fig. 4f). Consequently, the cloud warming effect increases in magnitude. In contrast to what is shown in Fig. 3, both the LWP scene $_{\text {and }}$ LWP $_{\text {cloud }}$ (Fig. 4b and c) show a difficult-to-interpret relationship with $\Delta F_{\text {ter }}$. Also, the relation between $r_{\text {eff }}$ and $I_{\text {org }}$ with $\Delta F_{\text {ter }}$ (panels $\mathrm{d}$ and e) is potentially masked by the dominating effects of cloud fraction and $z_{\mathrm{ct}}$. Additional methods are required to untangle these relationships.

In Fig. 4 , the lowest median $\Delta F_{\text {ter }}$ was observed during the flight conducted on 2 February (yellow diamond), while the highest one was on 11 February (blue square). The order of flights by increasing median $\Delta F_{\text {ter }}$ is different than that of increasing $\alpha_{\mathrm{ce}}$ in Fig. 3. In contrast to $\alpha_{\mathrm{ce}}$, the pattern of increasing median $\Delta F_{\text {ter }}$ with increasing cloud fraction is not as clear. The $z_{\mathrm{ct}}$ relationship, which is clearer in the scatter plot in Fig. 4, is not clearly captured in the pattern of the individual flights. This is perhaps due to the fact that, between days, other properties like the atmospheric profile are changing, which could mask the $z_{\mathrm{ct}}$ effect. For a constant temperature and humidity profile between days, we would expect the relation between $\Delta F_{\text {ter }}$ and $z_{\mathrm{ct}}$ to be clearer among the individual flights. Although it is poorly correlated in the subset of data as a whole, the most defined relationship found here between individual flights is with the organization of the cloud field, $I_{\text {org }}$. As the cloud field becomes more clustered, $\Delta F_{\text {ter }}$ decreases. This is in contrast to the results of Tobin et al. (2012), but their results pertain to deep convection, and here shallow clouds are the focus.

Looking again at some flights individually, we can deduce why the observations from different flights may look the way they do. If we look at the flight on 24 January (black circle), this flight stands out in Fig. 4a and b as having the highest median cloud fraction and $\mathrm{LWP}_{\text {scene }}$ but not the highest $\Delta F_{\text {ter }}$. The $\mathrm{LWP}_{\text {cloud }}$ is relatively low and the $\mathrm{R}_{\text {reff }}$ relatively large, and the cloud field has a middle range clustering compared to the other flights. The $z_{\mathrm{ct}}$ is also in a middle range. Using cloud fraction alone, we would expect a higher $\Delta F_{\text {ter }}$ relative to other clouds, but based on the results in this figure, the $I_{\text {org }}$ or $z_{\mathrm{ct}}$ could be factors dampening or overtaking the impact of cloud fraction. The high $z_{\mathrm{ct}}$ on the 9 February flight may also have a similar impact since the median $\Delta F_{\text {ter }}$ is high considering the low median cloud fraction and $\mathrm{LWP}_{\text {scene }}$ also observed during that flight.

\subsection{Standardized regression analysis}

To better understand the relative influence that different properties or the organization of the cloud field have, we use a parameter known as a beta coefficient (e.g., Neter et al., 1983; Bring, 1994). A beta coefficient represents the slope of the linear regression calculated for variables that have been standardized, so that they have a mean of 0 and a standard deviation of 1 . Standardization is simply carried out with

$Z=\frac{x-\mu}{\sigma}$,

where $Z$ is the standardized version of variable $x, \mu$ is the mean and $\sigma$ is the standard deviation. The benefit of using this method is that the variables are independent of their units, and the slopes of the linear regression of each cloud parameter with $\alpha_{\mathrm{ce}}$ and $\Delta F_{\mathrm{ter}}$ can be compared, thus indicating how much of a change in any one variable leads to a change in $\alpha_{\text {ce }}$ or $\Delta F_{\text {ter }}$, respectively.

Figure 5 shows the beta coefficients for each variable for the subset of flights as a whole as well as for individual flights. Cloud fraction and $\mathrm{LWP}_{\text {scene }}$ show the highest correlation with $\alpha_{\mathrm{ce}}$ for the subset of flights analyzed here (all flights) and for the individual flights. $z_{\mathrm{ct}}$ is also relatively high for all flights and some individual flights, whereas the correlations of the remaining parameters are low in most cases. It becomes clear that cloud fraction and $\mathrm{LWP}_{\text {scene }}$ are the main drivers of $\alpha_{\text {ce }}$ for both the campaign data set as a whole and for individual flights. The microphysical properties, on the other hand, are less straightforward to interpret. For all flights, neither $\mathrm{LWP}_{\text {cloud }}$ nor $r_{\text {eff }}$ demonstrates a strong correlation with $\alpha_{\text {ce }}$. The organization of the cloud field produces a similarly weak correlation.

Looking at individual flights, the overall correlation of $\mathrm{LWP}_{\text {cloud }}$ is weakly positive, but for flights on 24 and 28 January the LWP cloud $_{\text {demonstrates a stronger influence on }}$ $\alpha_{\mathrm{ce}} . r_{\mathrm{eff}}$ is also an interesting parameter due to the fact that, overall, and in some individual flight cases, it has a positive correlation with $\alpha_{\mathrm{ce}}$, while in other cases, like 31 January, the correlation is negative. Also, the importance of $z_{\mathrm{ct}}$ varies between flights, while the importance of $I_{\text {org }}$ maintains a low level of correlation with $\alpha_{\mathrm{ce}}$.

In the case of $\Delta F_{\text {ter }}$, for all flights and most of the individual flights, it is clear that the macrophysical properties are also the most highly correlated with $\Delta F_{\text {ter }}$ although not as strongly as with $\alpha_{\mathrm{ce}}$. Data from 28 January and 9 February show the $r_{\text {eff }}$ and $I_{\text {org }}$ to have the largest impact on $\Delta F_{\text {ter }}$ and with a magnitude stronger than what was observed for 

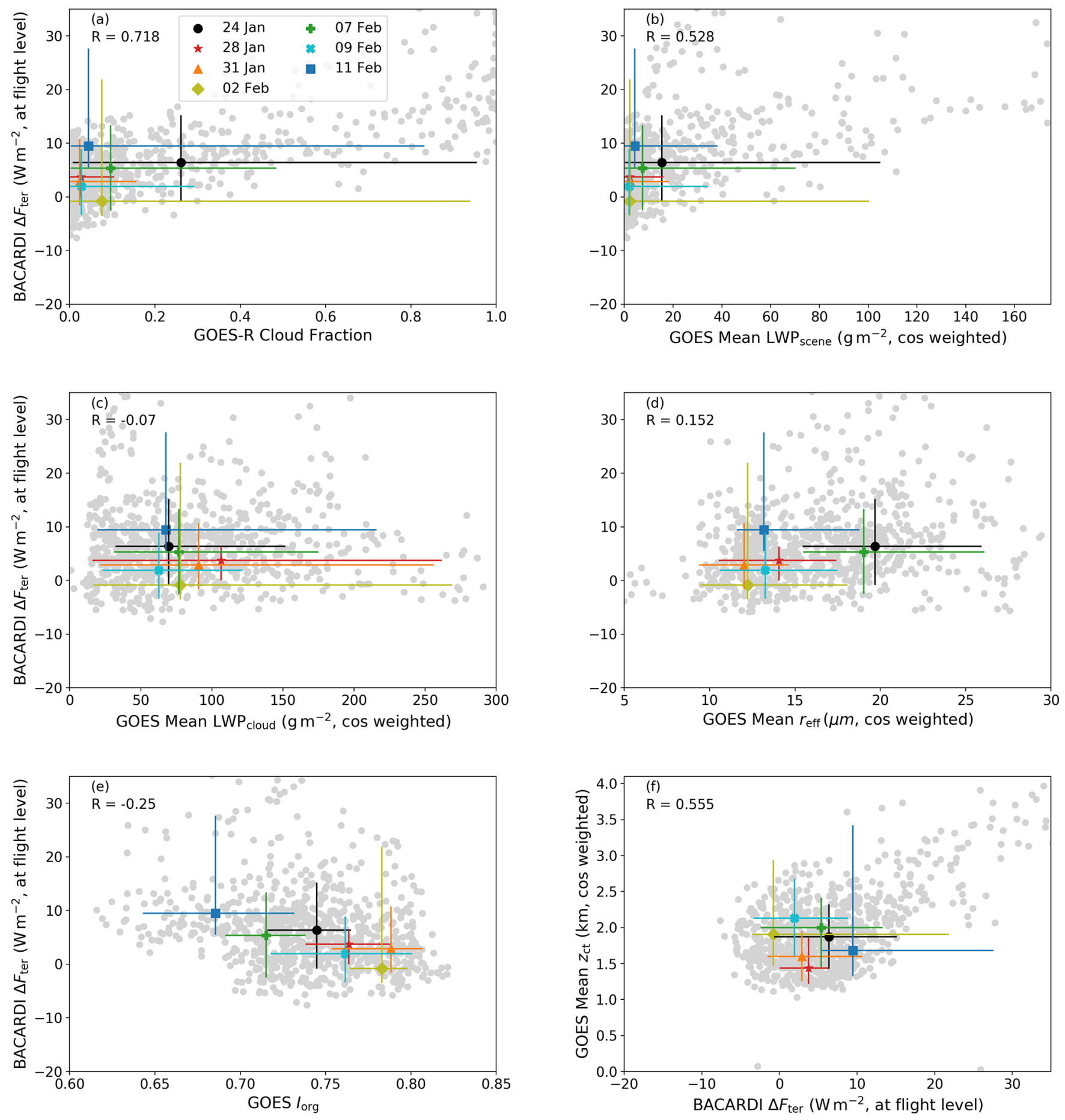

Figure 4. Same as Fig. 3 but for $\Delta F_{\text {ter. }}$

$\alpha_{\mathrm{ce}} \cdot z_{\mathrm{ct}}$ is also generally strongly positively correlated with $\Delta F_{\text {ter }} . I_{\text {org }}$ often demonstrates a stronger correlation with $\Delta F_{\text {ter }}$ than $\alpha_{\mathrm{ce}}$, but the positive or negative sign of that correlation changes from flight to flight, which suggests that the effects of this parameter could be linked to other properties or processes. Looking at all flights shows that correlation to be negative. $\mathrm{LWP}_{\text {cloud }}$ shows a mostly minor correlation with $\Delta F_{\text {ter. }}$.

It should be noted that, while the beta coefficients are a useful tool for pointing out the correlation of the different variables with $\alpha_{\mathrm{ce}}$ and $\Delta F_{\text {ter }}$, they are not necessarily good indicators of how the different variables work in concert with 


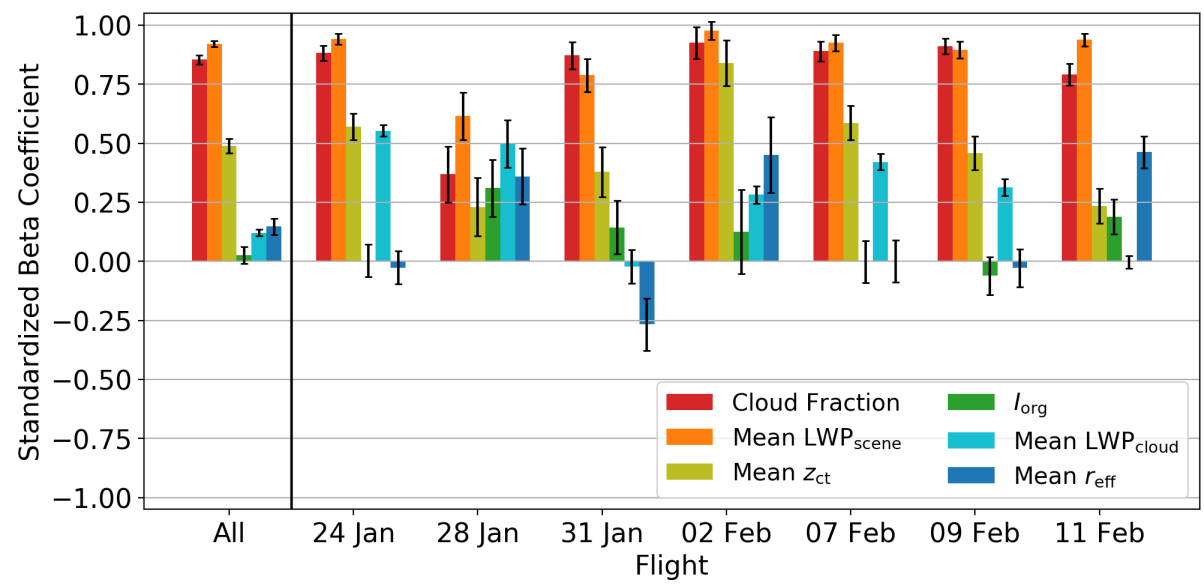

Figure 5. Beta coefficients demonstrating the relative correlation of different cloud properties and the organization of the cloud field to $\alpha_{\mathrm{ce}}$ for the subset of flights (all) and individual flights.

each other. Furthermore, the differences between flights rely very strongly on the individual distribution of the data for each flight. Because of the limited amount of data from each flight, outliers can significantly influence the results of a linear regression approach. In some cases it is not possible or is unreliable, as evidenced by the large error bars in Figs. 5 and 6 . Thus, such results should be interpreted with caution.

\subsection{Separation into cloud fraction regimes}

The analysis has shown that macrophysical properties, cloud fraction and LWP ${ }_{\text {scene }}$ are the main drivers of the $\alpha_{\text {ce }}$. To extract the impact of the microphysical properties, the data are divided into different cloud fraction classes - low cloud fraction for values below $33 \%$, middle cloud fraction for values between $33 \%$ and $66 \%$ and high cloud fraction for values greater than $66 \%$. This approach also allows for the exploration of those cases shown in Figs. 3 and 4, where the percentile range lines reveal that a large range of cloud fraction values were sampled in a single flight. The data are further categorized into different $\mathrm{LWP}_{\text {cloud }}, r_{\mathrm{eff}}, I_{\mathrm{org}}$ and $z_{\mathrm{ct}}$ ranges, and the results are shown in Fig. 7. It should be noted that, due to the limited amount of data, this evaluation is not carried out for individual flights, where we might expect to see certain details expressed differently for different situations.

The range of values observed in the data is of course much more diverse than what is shown here, but only small amounts of data are found at the extremes of those ranges. Thus, in an effort to preserve the statistical representativeness of the data, only cloud property bins with at least 10 data points are shown. This explains why the lowest cloud fraction bin has the largest ranges among the different cloud properties; the majority of the data observed during this campaign had low cloud fractions.

From this figure, the effect that different cloud properties have on cloud scenes of similar cloud fractions can be as- certained. For all cloud properties, an increase or decrease in that property has a limited effect on the $\alpha_{\mathrm{ce}}$ when the cloud fractions are low. Specifically, there is a weak increase in $\alpha_{\mathrm{ce}}$ with increasing LWP $\mathrm{Ploud}_{\text {and }} z_{\mathrm{ct}}$ and a weak decrease in $\alpha_{\mathrm{ce}}$ with increasing $r_{\text {eff. }}$ In the case of LWP $\mathrm{Lloud}_{\text {, this low cloud }}$ fraction line coincides with the consistent low $\alpha_{\text {ce }}$ mode in Fig. 3c. The impact of $I_{\text {org }}$ on $\alpha_{\text {ce }}$ for low cloud fractions is not clearly defined. When the cloud fractions are in the middle range, the impact of increasing $\mathrm{LWP}_{\text {cloud }}$ and $z_{\mathrm{ct}}$ becomes stronger, resulting in higher $\alpha_{\mathrm{ce}}$. Additionally, both $r_{\text {eff }}$ and $I_{\text {org }}$ show a weak positive correlation with $\alpha_{\mathrm{ce}}$. This is the first indication from the analyses presented here that the organization of the cloud field, in terms of the degree of clustering, has an impact on the solar radiative effects of the trade-wind cumuli. For high cloud fraction cases, the impact of all properties shown in Fig. 7 increases as indicated by the stronger slopes. With respect to $\mathrm{LWP}_{\text {cloud }}$, this characterizes the mode in Fig. $3 \mathrm{c}$, where an increase in $\mathrm{LWP}_{\text {cloud }}$ coincides with an increase in $\alpha_{\mathrm{ce}}$. Notably, around $3 \mathrm{~km}$, the $z_{\mathrm{ct}}$ reverses its correlation with $\alpha_{\mathrm{ce}}$ from positive to negative. This may be due to the limited amount of data in this cloud fraction and $z_{\mathrm{ct}}$ combination, which subsequently limits the representation of this group.

This result leads to the conclusion that, while macrophysical properties are the main driver of the $\alpha_{\mathrm{ce}}$, as cloud fraction increases, the microphysical properties as well as the horizontal cloud field organization and $z_{\text {ct }}$ make a greater contribution to the resulting $\alpha_{\mathrm{ce}}$. When cloud fraction values are low, the impact of those properties, regardless of magnitude, is minor.

Figure 8 shows how the relationship of different cloud properties with $\Delta F_{\text {ter }}$ changes when the cloud fraction is held constant. In the low cloud fraction group, the microphysical properties LWP cloud $_{\text {and }} r_{\text {eff }}$ appear to have no impact on $\Delta F_{\text {ter }}$ regardless of their magnitude. The impact of increasing $z_{\mathrm{ct}}$ is also minimal. The organization of the cloud 


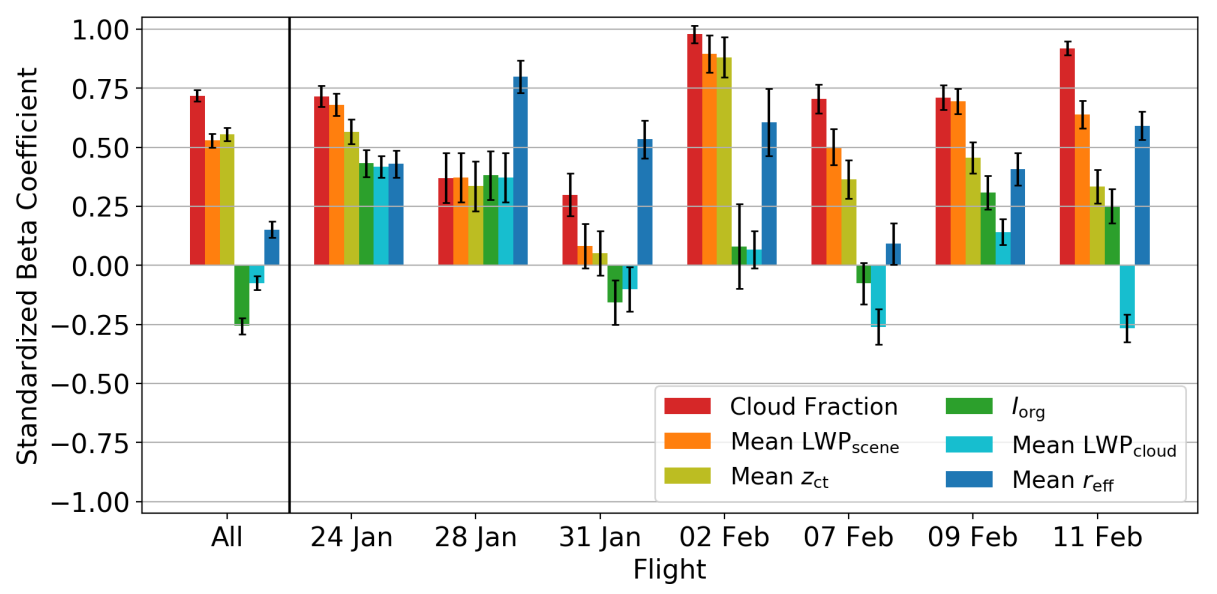

Figure 6. Same as Fig. 5 but for $\Delta F_{\text {ter. }}$
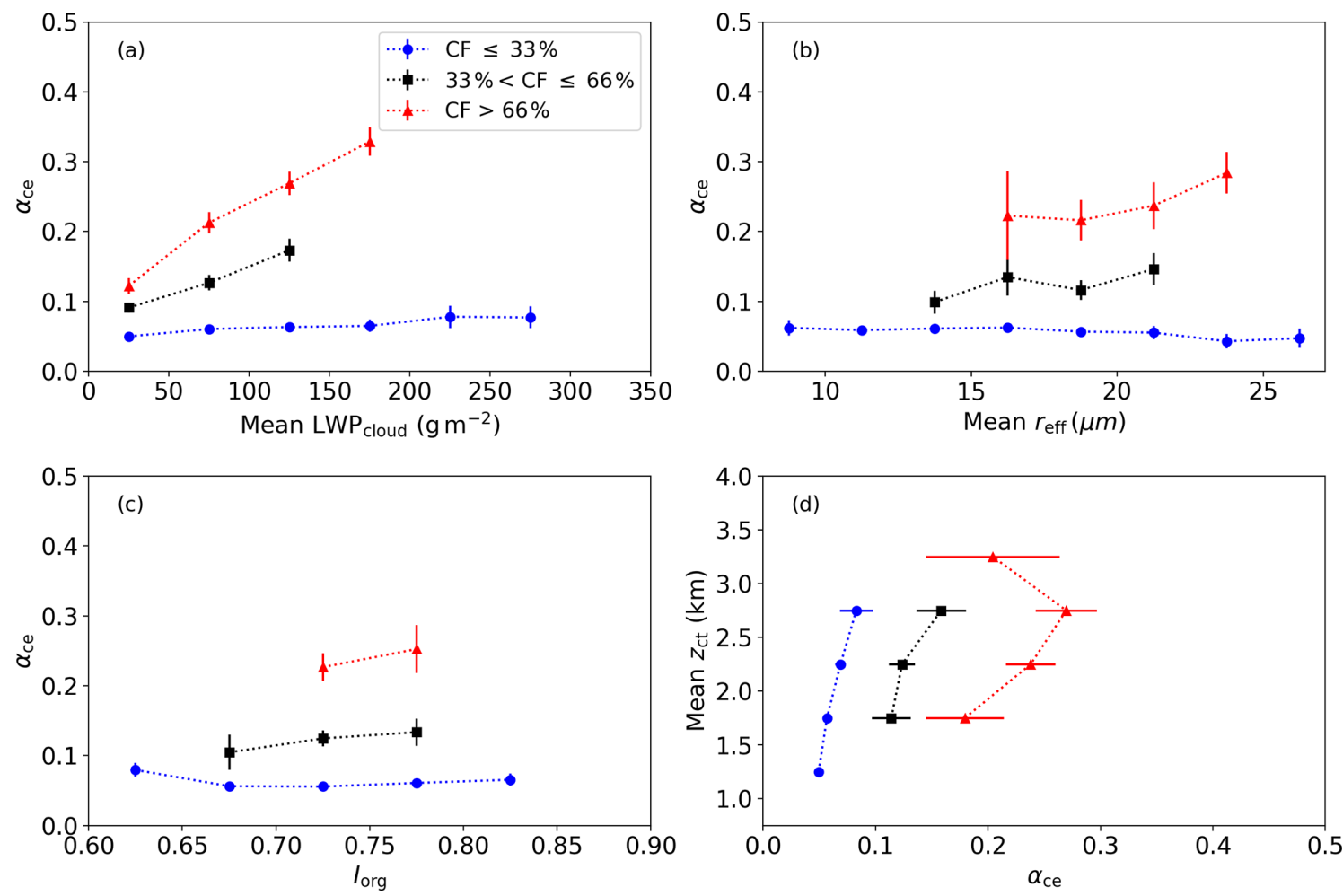

Figure 7. The relationship between $\alpha_{\mathrm{ce}}$ and different cloud properties also as a function of different cloud fraction classifications. (a) LWP cloud, (b) $r_{\text {eff }}$, (c) $I_{\text {org }}$ and (d) $z_{\text {ct }}$. The bars indicate $95 \%$ confidence intervals.

field shows a clearly negative impact on $\Delta F_{\text {ter }}$ for this cloud fraction class; as the clustering of the cloud field increases, the $\Delta F_{\text {ter }}$ decreases. For the middle cloud fraction range, the negative correlation with $I_{\text {org }}$ continues to be present. The relationship of $\Delta F_{\text {ter }}$ with $L W P_{\text {cloud }}$ and $r_{\text {eff }}$ also shows a negative correlation. In this cloud fraction range and the high cloud fraction range, the relationship of $\Delta F_{\text {ter }}$ with $z_{\mathrm{ct}}$ is even stronger. The impact of $I_{\text {org }}$ continues to have a negative correlation but does not appear to increase or decrease in strength relative to the other cloud fraction groups. The impacts of $\mathrm{LWP}_{\text {cloud }}$ and $r_{\text {eff }}$ are unclear for the high cloud fraction range. Given that they do not decrease with increasing $\Delta F_{\text {ter }}$, like in the middle cloud fraction regime, this could suggest that competing mechanisms are represented here. For example, because $\Delta F_{\text {ter }}$ is so strongly tied to $z_{\mathrm{ct}}$ at high cloud fractions, the effects of $\mathrm{LWP}_{\text {cloud }}$ could be masked by the combination of high and low clouds in the high cloud fraction class. Thus, it could be necessary to further categorize 

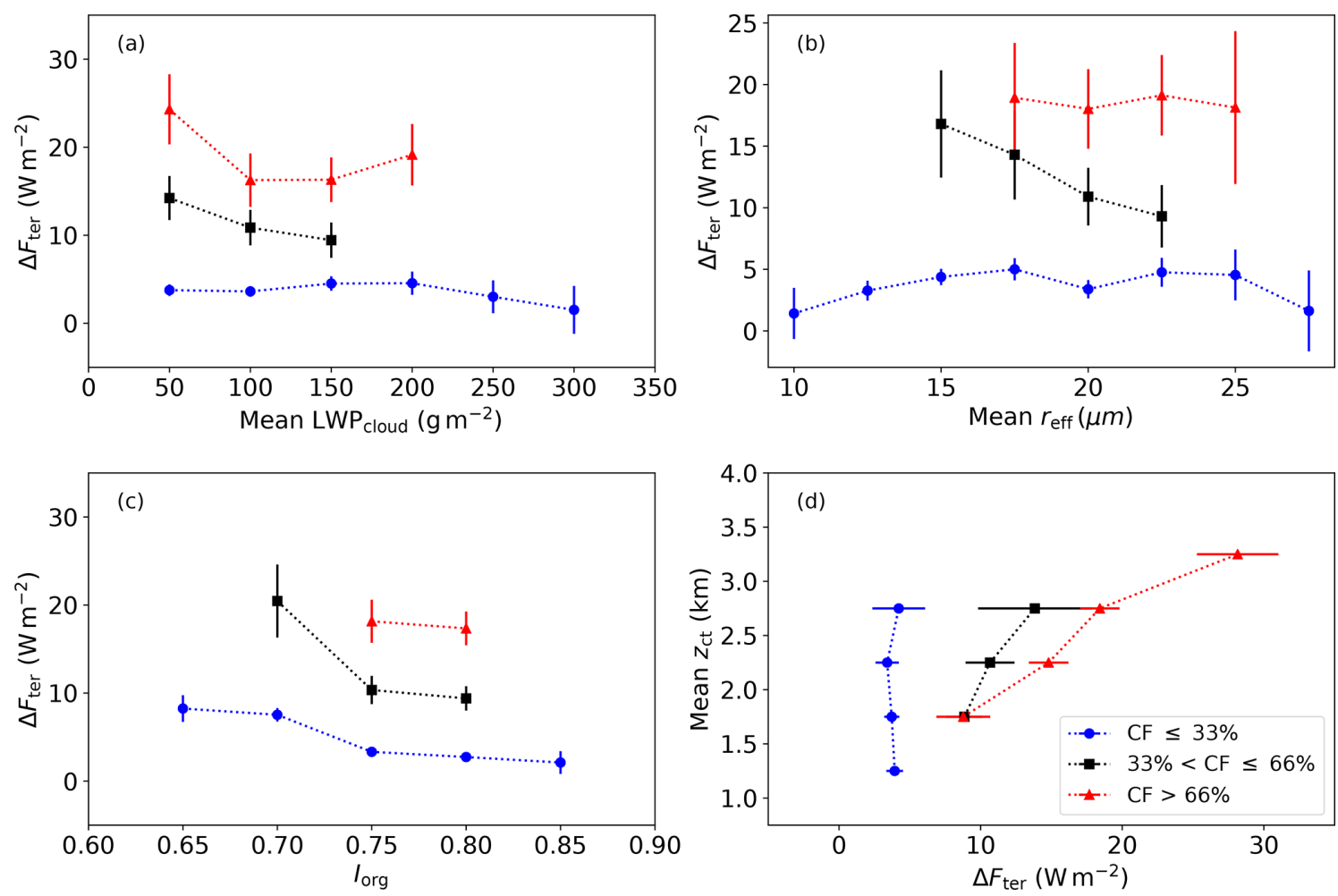

Figure 8. Same as Fig. 7 but for $\Delta F_{\text {ter. }}$.

the data by cloud top height or other macrophysical characteristics before drawing any conclusions about the effects of microphysical cloud properties.

\section{Discussion and conclusions}

Bringing together a comprehensive characterization of tradewind clouds based on their macrophysical and microphysical properties and interactions is a challenge, one reason being the lack of representative observational data sets. The recent EUREC ${ }^{4} \mathrm{~A}$ campaign provides a solid database to resolve this issue. In this study, we assess how different cloud properties - cloud fraction, mean liquid water path including cloudy and cloud-free pixels in the scene $\left(\mathrm{LWP}_{\text {scene }}\right)$, mean liquid water path of only the cloudy pixels in the scene $\left(\mathrm{LWP}_{\text {cloud }}\right)$, droplet effective radius $\left(r_{\text {eff }}\right)$, cloud top height $\left(z_{\mathrm{ct}}\right)$ and the organization of the cloud field $\left(I_{\mathrm{org}}\right)$ - affect the cloud radiative forcing of shallow trade-wind clouds and to what degree these parameters matter relative to each other. Using irradiance observations from the BACARDI broadband radiometer on board HALO, we calculate the solar and terrestrial cloud radiative effects, here represented by $\alpha_{\text {ce }}$ and $\Delta F_{\text {ter }}$. The cloud properties are obtained via 1 min collocated cloud products from GOES-16.

The relationships between cloud radiative forcing and different cloud properties are complex and a challenge to disentangle. However, we have demonstrated that it is possible to use a combination of airborne irradiance measurements and satellite-based cloud property observations for this purpose. For both the solar and terrestrial components, we find that the macrophysical properties, cloud fraction and $\mathrm{LWP}_{\text {scene }}$ are the main drivers of changes in the radiative forcing of trade-wind clouds. For the solar component, in cases where the cloud fraction is below $33 \%$, we observe that cloud microphysical properties, $z_{\mathrm{ct}}$ and the organization of the cloud field are of minor importance for determining the cloud radiative forcing, demonstrating weak or no impact on the $\alpha_{\mathrm{ce}}$. As the cloud fraction increases, the relevance of those additional quantities also increases. For the terrestrial component, the impact of $z_{\mathrm{ct}}$ and $\Delta F_{\mathrm{ter}}$ strengthens with increasing cloud fraction. $I_{\text {org }}$ also demonstrates a consistent negative impact on $\Delta F_{\text {ter }}$ at any cloud fraction, while the impacts of $L W P_{\text {cloud }}$ and $r_{\text {eff }}$ are more difficult to interpret.

In comparison to each other, the solar component is more strongly positively correlated with $\mathrm{LWP}_{\text {cloud }}$ and $r_{\text {eff }}$. The correlations with $z_{\mathrm{ct}}$ and $I_{\mathrm{org}}$ are weakly positive for $\alpha_{\mathrm{ce}}$. This is in contrast to $\Delta F_{\text {ter }}$, where the positive correlation with $z_{\mathrm{ct}}$ is much stronger, particularly as cloud fraction increases, and the correlation with $I_{\text {org }}$ is also strong but negative. This last point indicates that, as the cloud field becomes more clustered, the terrestrial cloud radiative effects decrease, while the $\alpha_{\mathrm{ce}}$ increases slightly. With these points in mind, it should be possible to discern a general idea of the cloud radiative 
forcing by looking only at the properties of a cloud field based on satellite measurements.

In those instances where certain relations were unclear, it could be possible that the addition of other information or ways of categorizing the data could be the key to extracting even more clear conclusions. Here, the results should be constrained to specific cloud types observed during EUREC ${ }^{4} \mathrm{~A}$, which are largely a mixture of shallow cumulus and low stratiform clouds. This could be further extended to categorization based on the description of four cloud types given in Schulz et al. (2021). Also, using $I_{\text {org }}$ as the parameter for defining the organization of the cloud field may do so correctly in a macrophysical sense, but it fails to capture other important qualities about the clouds, such as the optical thickness, which other methods for describing cloud morphology capture more effectively (McCoy et al., 2017). Furthermore, the complexities of better understanding the relation of $r_{\text {eff }}$ to cloud radiative forcing may be found by separating precipitating versus non-precipitating clouds (Lohmann et al., 2000).

Another point to consider is the fact that the cloud fraction or organization of the cloud field may not be accurately depicted due to the coarse resolution of GOES-16. Coarse resolution leads to missing small clouds, cloud fractions that are overestimated, and reflectances that are falsely attributed to cloudy and cloud-free pixels (Koren et al., 2008). However, because the cloud radiative forcing is calculated from airborne observations in this study, we do not expect the irradiance observations to be falsely representative of cloudy-sky conditions. Also, by adjusting the BACARDI footprint used for this study to be compatible with the reflectance observations of GOES, we are ensuring a fair comparison. Nevertheless, the question remains concerning whether higherresolution observations of cloud properties are necessary for determining which cloud properties drive the cloud radiative forcing. To answer this, additional work is planned for a subsequent study including imaging remote sensing at a high spatial resolution (below $10 \mathrm{~m}$ ), such as the VELOX thermal IR camera that was also present on board HALO during EUREC ${ }^{4} \mathrm{~A}$.

\section{Appendix A: BACARDI footprint quality check}

As mentioned in Sect. 2.4, the irradiance measured by BACARDI may not necessarily be compatible with the radiation measured by GOES-16 within the full BACARDI footprint size. Therefore, as a quality check, we compared the calculated $\alpha_{\text {ce }}$ from BACARDI to the mean reflectance from the $0.65 \mu \mathrm{m}$ channel for footprints of varying sizes cut out from GOES-16. Because we are comparing different quantities, they will not match exactly, but we assume that the footprint size at which they show the best correlation represents a footprint size where GOES-16 mean footprint reflectance is comparable to BACARDI irradiance. A FOV of $102^{\circ}$ was found to provide the best correlation $(R=0.968)$. An example of this comparison from the flight on 24 January 2020 for a FOV of $102^{\circ}$ is shown in Fig. A1b. The same comparisons for FOVs of $62^{\circ}$ and $142^{\circ}$ are also shown in Fig. A1a and c, respectively, to demonstrate that $102^{\circ}$ is the best solution. Based on the selected FOV and a typical flight altitude of $10 \mathrm{~km}$, the most appropriate footprint size has a radius of approximately $13 \mathrm{~km}$. 

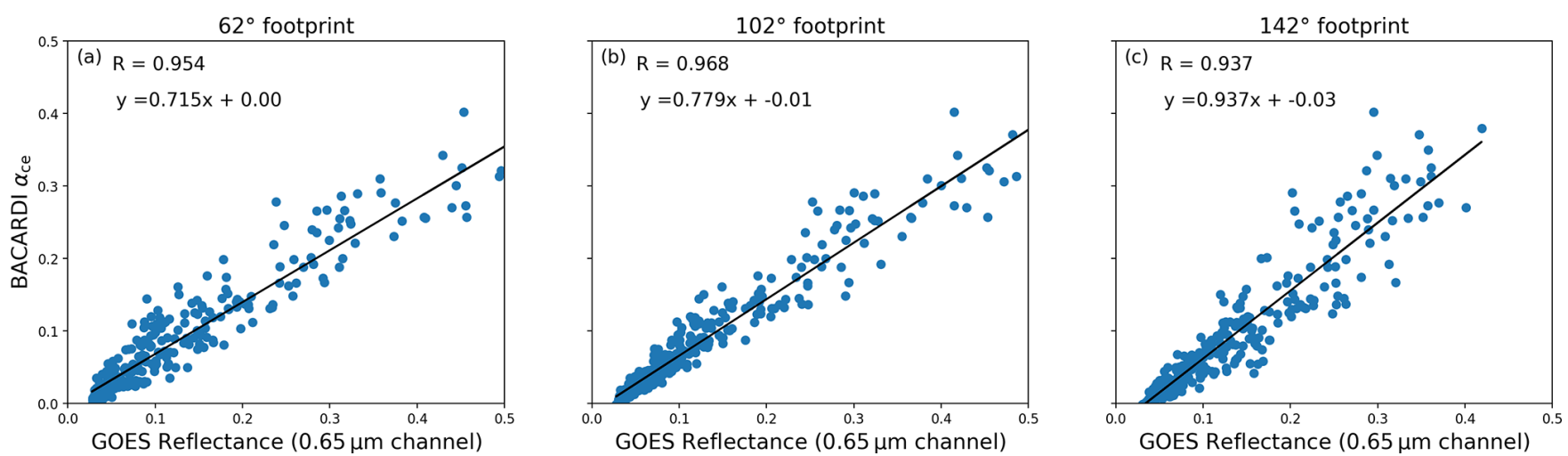

Figure A1. Comparison of $\alpha_{\mathrm{ce}}$ from BACARDI and the mean reflectance from the $0.65 \mu \mathrm{m}$ channel of GOES-16 for a FOV of (a) $62^{\circ}$, (b) $102^{\circ}$ and (c) $142^{\circ}$ from the flight on 24 January 2020. The data used here correspond to the location of the circle flight pattern given in Sect. 2.1 at a typical flight altitude of approximately $10 \mathrm{~km}$. The exact measurement times can be found in Table 2 .

Data availability. Time series of the BACARDI observations are published in AERIS by Ehrlich et al. (2021). All other data produced for this study from BACARDI are available upon request from the leading author. The dropsonde data used in this study are published in AERIS by George (2021). The source for the GOES16 data set used in this study is the National Oceanic and Atmospheric Administration (NOAA)/National Environmental Satellite, Data, and Information Service (NESDIS) and the University of Wisconsin-Madison/Cooperative Institute for Meteorological Satellite Studies (CIMSS)

Author contributions. AL is the primary author of the paper. AE, MS, KW, and MW carried out the airborne experimental work. Simulations with libRadtran were performed by $\mathrm{KW}$ and $\mathrm{AE}$. AL, AE, and $\mathrm{KW}$ analyzed and compared the observations and simulations. All the authors contributed to the interpretation of the results and wrote the paper.

Competing interests. The contact author has declared that neither they nor their co-authors have any competing interests.

Disclaimer. Publisher's note: Copernicus Publications remains neutral with regard to jurisdictional claims in published maps and institutional affiliations.
Acknowledgements. We thank the Max Planck Institute for Meteorology for designing and coordinating the EUREC ${ }^{4} \mathrm{~A}$ campaign and the German Aerospace Center (Deutsches Luft und Raumfahrtzentrum, DLR) for campaign support. We also thank the NOAA/NESDIS and University of Wisconsin-Madison/CIMSS team for providing the dedicated EUREC ${ }^{4} \mathrm{~A}$ GOES-16 data set. We are grateful to Hartwig Deneke, Theresa Mieslinger and Marcus Klingebiel for helpful discussions and support that contributed to this work.

Financial support. This research has been supported by the Deutsche Forschungsgemeinschaft (DFG) within the HALO SPP 1294 (grant nos. 422897361 and 316646266 ).

Review statement. This paper was edited by Farahnaz Khosrawi and reviewed by two anonymous referees.

\section{References}

Ardanuy, P. E., Stowe, L. L., Gruber, A., Weiss, M. and Long, C. S.: Longwave Cloud Radiative Forcing as Determined from Nimbus-7 Observations, J. Climate, 2, 766-799, https://doi.org/10.1175/15200442(1989)002<0766:LCRFAD>2.0.CO;2, 1988.

Bender, F. A.-M., Charlson, R. J., Ekman, A. M. L., and Leahy, L. V.: Quantification of Monthly Mean Regional-Scale Albedo of Marine Stratiform Clouds in Satellite Observations and GCMs, J. Appl. Meteorol. Clim., 50, 2139-2148, https://doi.org/10.1175/JAMC-D-11-049.1, 2011.

Bender, F. A.-M., Engström, A., and Karlsson, J.: Factors Controlling Cloud Albedo in Marine Subtropical Stratocumulus Regions in Climate Models and Satellite Observations, J. Climate, 29, 3559-3587, https://doi.org/10.1175/JCLI-D-15-0095.1, 2016.

Bony, S., Stevens, B., Ament, F., Bigorre, S., Chazette, P., Crewell, S., Delanoë, J., Emanuel, K., Farrell, D., Flamant, C., Gross, S., Hirsch, L., Karstensen, J., Mayer, B., Nuijens, L., Ruppert, 
J. H., Sandu, I., Siebesma, P., Speich, S., Szczap, F., Totems, J., Vogel, R., Wendisch, M., and Wirth, M.: EUREC ${ }^{4}$ A: A Field Campaign to Elucidate the Couplings Between Clouds, Convection and Circulation, Surv. Geophys., 38, 1529-1568, https://doi.org/10.1007/s10712-017-9428-0, 2017.

Bring, J.: How to Standardize Regression Coefficients, Am. Stat., 48, 209-213, https://doi.org/10.2307/2684719, 1994.

Chen, T., Rossow, W. B., and Zhang, Y.: Radiative Effects of Cloud-Type Variations, J. Climate, $\quad 13, \quad 264-286, \quad$ https://doi.org/10.1175/15200442(2000)013<0264:REOCTV>2.0.CO;2, 2000.

Diamond, M. S., Director, H. M., Eastman, R., Possner, A., and Wood, R.: Substantial Cloud Brightening From Shipping in Subtropical Low Clouds, AGU Advances, 1, e2019AV000111, https://doi.org/10.1029/2019AV000111, 2020.

Ehrlich, A. and Wendisch, M.: Reconstruction of high-resolution time series from slow-response broadband terrestrial irradiance measurements by deconvolution, Atmos. Meas. Tech., 8, 36713684, https://doi.org/10.5194/amt-8-3671-2015, 2015.

Ehrlich, A., Wolf, K., Luebke, A., Zoeger, M., and Giez, A.: Broadband solar and terrestrial, upward and downward irradiance measured by BACARDI on HALO during the EUREC ${ }^{4}$ A Field Campaign, AERIS [data set], https://doi.org/10.25326/160, 2021.

Emde, C., Buras-Schnell, R., Kylling, A., Mayer, B., Gasteiger, J., Hamann, U., Kylling, J., Richter, B., Pause, C., Dowling, T., and Bugliaro, L.: The libRadtran software package for radiative transfer calculations (version 2.0.1), Geosci. Model Dev., 9, 1647-1672, https://doi.org/10.5194/gmd-9-1647-2016, 2016.

Engström, A., Bender, F. A.-M., Charlson, R. J., and Wood, R.: The nonlinear relationship between albedo and cloud fraction on near-global, monthly mean scale in observations and in the CMIP5 model ensemble, Geophys. Res. Lett., 42, 9571-9578, https://doi.org/10.1002/2015GL066275, 2015.

George, G.: JOANNE: Joint dropsonde Observations of the Atmosphere in tropical North atlaNtic meso-scale Environments (v2.0.0), AERIS [data set], https://doi.org/10.25326/246, 2021.

George, G., Stevens, B., Bony, S., Pincus, R., Fairall, C., Schulz, H., Kölling, T., Kalen, Q. T., Klingebiel, M., Konow, H., Lundry, A., Prange, M., and Radtke, J.: JOANNE: Joint dropsonde Observations of the Atmosphere in tropical North atlaNtic mesoscale Environments, Earth Syst. Sci. Data, 13, 5253-5272, https://doi.org/10.5194/essd-13-5253-2021, 2021.

George, R. C. and Wood, R.: Subseasonal variability of low cloud radiative properties over the southeast Pacific Ocean, Atmos. Chem. Phys., 10, 4047-4063, https://doi.org/10.5194/acp-104047-2010, 2010.

Heidinger, A.: Algorithm Theoretical Basis Document: ABI Cloud Height, Version 3.0, NOAA NESDIS Center for Satellite Applications and Research, College Park, MD, USA, https: //www.star.nesdis.noaa.gov/goesr/documents/ATBDs/Baseline/ ATBD_GOES-R_Cloud\%20Height_v3.0_July\%202012.pdf (last access: 26 January 2022), 2012.

Heidinger, A. and Straka, W. C.: Algorithm Theoretical Basis Document: ABI Cloud Mask, Version 3.0, NOAA NESDIS Center for Satellite Applications and Research, College Park, MD, USA, https://www.star.nesdis.noaa.gov/goesr/documents/ ATBDs/Baseline/ATBD_GOES-R_Cloud_Mask_v3.0_July\% 202012.pdf (last access: 26 January 2022), 2012.
Herwehe, J. A., Alapaty, K., Spero, T. L., and Nolte, C. G.: Increasing the credibility of regional climate simulations by introducing subgrid-scale cloud-radiation interactions, J. Geophys. Res.-Atmos., 119, 5317-5330, https://doi.org/10.1002/2014JD021504, 2014.

Jacob, M., Ament, F., Gutleben, M., Konow, H., Mech, M., Wirth, M., and Crewell, S.: Investigating the liquid water path over the tropical Atlantic with synergistic airborne measurements, Atmos. Meas. Tech., 12, 3237-3254, https://doi.org/10.5194/amt12-3237-2019, 2019.

Jiménez, P. A.: Assessment of the GOES-16 Clear Sky Mask Product over the Contiguous USA Using CALIPSO Retrievals, Remote Sens.-Basel, 12, 1630, https://doi.org/10.3390/rs12101630, 2020.

Khain, A. P., Beheng, K. D., Heymsfield, A., Korolev, A., Krichak, S. O., Levin, Z., Pinsky, M., Phillips, V., Prabhakaran, T., Teller, A., van den Heever, S. C., and Yano, J.-I.: Representation of microphysical processes in cloud-resolving models: Spectral (bin) microphysics versus bulk parameterization, Rev. Geophys., 53, 247-322, https://doi.org/10.1002/2014RG000468, 2015.

Kipp and Zonen B.V: Instruction Manual CG4 Pyrgeometer, Delft, Netherlands, https://www.kippzonen.com/Download/38/ Manual-CGR4-Pyrgeometer (last access: 26 January 2022), 2014.

Kipp and Zonen B.V: Instruction Manual CMP Series Pyranometer, Delft, Netherlands, https://www.kippzonen.com/Download/72/ Manual-Pyranometers-CMP-series-English (last access: 26 January 2022), 2016.

Klein, S. A., Hall, A., Norris, J. R., and Pincus, R.: Low-Cloud Feedbacks from Cloud-Controlling Factors: A Review, Surv. Geophys., 38, 1307-1329, https://doi.org/10.1007/s10712-0179433-3, 2017.

Konow, H., Ewald, F., George, G., Jacob, M., Klingebiel, M., Kölling, T., Luebke, A. E., Mieslinger, T., Pörtge, V., Radtke, J., Schäfer, M., Schulz, H., Vogel, R., Wirth, M., Bony, S., Crewell, S., Ehrlich, A., Forster, L., Giez, A., Gödde, F., Groß, S., Gutleben, M., Hagen, M., Hirsch, L., Jansen, F., Lang, T., Mayer, B., Mech, M., Prange, M., Schnitt, S., Vial, J., Walbröl, A., Wendisch, M., Wolf, K., Zinner, T., Zöger, M., Ament, F., and Stevens, B.: EUREC4A's HALO, Earth Syst. Sci. Data, 13, 55455563, https://doi.org/10.5194/essd-13-5545-2021, 2021.

Koren, I., Oreopoulos, L., Feingold, G., Remer, L. A., and Altaratz, O.: How small is a small cloud?, Atmos. Chem. Phys., 8, 38553864, https://doi.org/10.5194/acp-8-3855-2008, 2008.

Lohmann, U., Tselioudis, G., and Tyler, C.: Why is the cloud albedo - Particle size relationship different in optically thick and optically thin clouds?, Geophys. Res. Lett., 27, 1099-1102, https://doi.org/10.1029/1999GL011098, 2000.

McCoy, I. L., Wood, R., and Fletcher, J. K.: Identifying Meteorological Controls on Open and Closed Mesoscale Cellular Convection Associated with Marine Cold Air Outbreaks, J. Geophys. Res.-Atmos., 122, 11678-11702, https://doi.org/10.1002/2017JD027031, 2017.

Mieslinger, T., Horváth, A., Buehler, S. A., and Sakradzija, M.: The Dependence of Shallow Cumulus Macrophysical Properties on Large-Scale Meteorology as Observed in ASTER Imagery, J. Geophys. Res.-Atmos., 124, 11477-11505, https://doi.org/10.1029/2019JD030768, 2019. 
Neter, J., Wasserman, W., and Kutner, M.: Applied Linear Regression Models, 1st edn., Richard D. Irwin, Inc., Homewood, IL, USA, ISBN 0-256-02547-9 1983.

Nuijens, L., Serikov, I., Hirsch, L., Lonitz, K., and Stevens, B.: The distribution and variability of low-level cloud in the North Atlantic trades, Q. J. Roy. Meteor. Soc., 140, 2364-2374, https://doi.org/10.1002/qj.2307, 2014.

Painemal, D., Spangenberg, D., Smith Jr., W. L., Minnis, P., Cairns, B., Moore, R. H., Crosbie, E., Robinson, C., Thornhill, K. L., Winstead, E. L., and Ziemba, L.: Evaluation of satellite retrievals of liquid clouds from the GOES-13 imager and MODIS over the midlatitude North Atlantic during the NAAMES campaign, Atmos. Meas. Tech., 14, 6633-6646, https://doi.org/10.5194/amt14-6633-2021, 2021.

Peng, Y., Lohmann, U., Leaitch, R., Banic, C., and Couture, M.: The cloud albedo-cloud droplet effective radius relationship for clean and polluted clouds from RACE and FIRE.ACE, J. Geophys. Res.-Atmos., 107, AAC1-1-AAC1-6, https://doi.org/10.1029/2000JD000281, 2002.

Schäfer, M., Wolf, K., Ehrlich, A., Hallbauer, C., Jäkel, E., Jansen, F., Luebke, A. E., Müller, J., Thoböll, J., Röschenthaler, T., Stevens, B., and Wendisch, M.: VELOX - A new thermal infrared imager for airborne remote sensing of cloud and surface properties, Atmos. Meas. Tech. Discuss. [preprint], https://doi.org/10.5194/amt-2021-341, accepted, 2021.

Schmit, T., Lindstrom, S., Gerth, J., and Gunshor, M.: Applications of the 16 Spectral Bands on the Advanced Baseline Imager (ABI), J. Oper. Meteor., 6, 33-46, https://doi.org/10.15191/nwajom.2018.0604, 2018.

Schmit, T. J., Griffith, P., Gunshor, M. M., Daniels, J. M., Goodman, S. J., and Lebair, W. J.: A Closer Look at the ABI on the GOES-R Series, B. Am. Meteorol. Soc., 98, 681-698, https://doi.org/10.1175/BAMS-D-15-00230.1, 2017.

Schnitt, S., Orlandi, E., Mech, M., Ehrlich, A., and Crewell, S.: Characterization of Water Vapor and Clouds During the Next-Generation Aircraft Remote Sensing for Validation (NARVAL) South Studies, IEEE J. Sel. Top. Appl., 10, 3114-3124, https://doi.org/10.1109/JSTARS.2017.2687943, 2017.

Schulz, H., Eastman, R., and Stevens, B.: Characterization and Evolution of Organized Shallow Convection in the Downstream North Atlantic Trades, J. Geophys. Res.-Atmos., 126, e2021JD034575, https://doi.org/10.1029/2021JD034575, 2021.

Siebert, H., Beals, M., Bethke, J., Bierwirth, E., Conrath, T., Dieckmann, K., Ditas, F., Ehrlich, A., Farrell, D., Hartmann, S., Izaguirre, M. A., Katzwinkel, J., Nuijens, L., Roberts, G., Schäfer, M., Shaw, R. A., Schmeissner, T., Serikov, I., Stevens, B., Stratmann, F., Wehner, B., Wendisch, M., Werner, F., and Wex, H.: The fine-scale structure of the trade wind cumuli over Barbados - an introduction to the CARRIBA project, Atmos. Chem. Phys., 13, 10061-10077, https://doi.org/10.5194/acp-13-100612013, 2013.

Stapf, J., Ehrlich, A., and Wendisch, M.: Influence of Thermodynamic State Changes on Surface Cloud Radiative Forcing in the Arctic: A Comparison of Two Approaches Using Data From AFLUX and SHEBA, J. Geophys. Res.-Atmos., 126, e2020JD033589, https://doi.org/10.1029/2020JD033589, 2021.

Stevens, B., Ament, F., Bony, S., Crewell, S., Ewald, F., Gross, S., Hansen, A., Hirsch, L., Jacob, M., Kölling, T., Konow, H., Mayer, B., Wendisch, M., Wirth, M., Wolf, K., Bakan, S.,
Bauer-Pfundstein, M., Brueck, M., Delanoë, J., Ehrlich, A., Farrell, D., Forde, M., Gödde, F., Grob, H., Hagen, M., Jäkel, E., Jansen, F., Klepp, C., Klingebiel, M., Mech, M., Peters, G., Rapp, M., Wing, A. A., and Zinner, T.: A High-Altitude Long-Range Aircraft Configured as a Cloud Observatory: The NARVAL Expeditions, B. Am. Meteorol. Soc., 100, 1061-1077, https://doi.org/10.1175/BAMS-D-18-0198.1, 2019.

Stevens, B., Bony, S., Farrell, D., Ament, F., Blyth, A., Fairall, C., Karstensen, J., Quinn, P. K., Speich, S., Acquistapace, C., Aemisegger, F., Albright, A. L., Bellenger, H., Bodenschatz, E., Caesar, K.-A., Chewitt-Lucas, R., de Boer, G., Delanoë, J., Denby, L., Ewald, F., Fildier, B., Forde, M., George, G., Gross, S., Hagen, M., Hausold, A., Heywood, K. J., Hirsch, L., Jacob, M., Jansen, F., Kinne, S., Klocke, D., Kölling, T., Konow, H., Lothon, M., Mohr, W., Naumann, A. K., Nuijens, L., Olivier, L., Pincus, R., Pöhlker, M., Reverdin, G., Roberts, G., Schnitt, S., Schulz, H., Siebesma, A. P., Stephan, C. C., Sullivan, P., TouzéPeiffer, L., Vial, J., Vogel, R., Zuidema, P., Alexander, N., Alves, L., Arixi, S., Asmath, H., Bagheri, G., Baier, K., Bailey, A., Baranowski, D., Baron, A., Barrau, S., Barrett, P. A., Batier, F., Behrendt, A., Bendinger, A., Beucher, F., Bigorre, S., Blades, E., Blossey, P., Bock, O., Böing, S., Bosser, P., Bourras, D., BouruetAubertot, P., Bower, K., Branellec, P., Branger, H., Brennek, M., Brewer, A., Brilouet , P.-E., Brügmann, B., Buehler, S. A., Burke, E., Burton, R., Calmer, R., Canonici, J.-C., Carton, X., Cato Jr., G., Charles, J. A., Chazette, P., Chen, Y., Chilinski, M. T., Choularton, T., Chuang, P., Clarke, S., Coe, H., Cornet, C., Coutris, P., Couvreux, F., Crewell, S., Cronin, T., Cui, Z., Cuypers, Y., Daley, A., Damerell, G. M., Dauhut, T., Deneke, H., Desbios, J.-P., Dörner, S., Donner, S., Douet, V., Drushka, K., Dütsch, M., Ehrlich, A., Emanuel, K., Emmanouilidis, A., Etienne, J.-C., Etienne-Leblanc, S., Faure, G., Feingold, G., Ferrero, L., Fix, A., Flamant, C., Flatau, P. J., Foltz, G. R., Forster, L., Furtuna, I., Gadian, A., Galewsky, J., Gallagher, M., Gallimore, P., Gaston, C., Gentemann, C., Geyskens, N., Giez, A., Gollop, J., Gouirand, I., Gourbeyre, C., de Graaf, D., de Groot, G. E., Grosz, R., Güttler, J., Gutleben, M., Hall, K., Harris, G., Helfer, K. C., Henze, D., Herbert, C., Holanda, B., Ibanez-Landeta, A., Intrieri, J., Iyer, S., Julien, F., Kalesse, H., Kazil, J., Kellman, A., Kidane, A. T., Kirchner, U., Klingebiel, M., Körner, M., Kremper, L. A., Kretzschmar, J., Krüger, O., Kumala, W., Kurz, A., L'Hégaret, P., Labaste, M., Lachlan-Cope, T., Laing, A., Landschützer, P., Lang, T., Lange, D., Lange, I., Laplace, C., Lavik, G., Laxenaire, R., Le Bihan, C., Leandro, M., Lefevre, N., Lena, M., Lenschow, D., Li, Q., Lloyd, G., Los, S., Losi, N., Lovell, O., Luneau, C., Makuch, P., Malinowski, S., Manta, G., Marinou, E., Marsden, N., Masson, S., Maury, N., Mayer, B., MayersAls, M., Mazel, C., McGeary, W., McWilliams, J. C., Mech, M., Mehlmann, M., Meroni, A. N., Mieslinger, T., Minikin, A., Minnett, P., Möller, G., Morfa Avalos, Y., Muller, C., Musat, I., Napoli, A., Neuberger, A., Noisel, C., Noone, D., Nordsiek, F., Nowak, J. L., Oswald, L., Parker, D. J., Peck, C., Person, R., Philippi, M., Plueddemann, A., Pöhlker, C., Pörtge, V., Pöschl, U., Pologne, L., Posyniak, M., Prange, M., Quiñones Meléndez, E., Radtke, J., Ramage, K., Reimann, J., Renault, L., Reus, K., Reyes, A., Ribbe, J., Ringel, M., Ritschel, M., Rocha, C. B., Rochetin, N., Röttenbacher, J., Rollo, C., Royer, H., Sadoulet, P., Saffin, L., Sandiford, S., Sandu, I., Schäfer, M., Schemann, V., Schirmacher, I., Schlenczek, O., Schmidt, J., Schröder, M., 
Schwarzenboeck, A., Sealy, A., Senff, C. J., Serikov, I., Shohan, S., Siddle, E., Smirnov, A., Späth, F., Spooner, B., Stolla, M. K., Szkółka, W., de Szoeke, S. P., Tarot, S., Tetoni, E., Thompson, E., Thomson, J., Tomassini, L., Totems, J., Ubele, A. A., Villiger, L., von Arx, J., Wagner, T., Walther, A., Webber, B., Wendisch, M., Whitehall, S., Wiltshire, A., Wing, A. A., Wirth, M., Wiskandt, J., Wolf, K., Worbes, L., Wright, E., Wulfmeyer, V., Young, S., Zhang, C., Zhang, D., Ziemen, F., Zinner, T., and Zöger, M.: EUREC ${ }^{4}$ A, Earth Syst. Sci. Data, 13, 4067-4119, https://doi.org/10.5194/essd-13-4067-2021, 2021.

Tobin, I., Bony, S., and Roca, R.: Observational Evidence for Relationships between the Degree of Aggregations of Deep Convection, Water Vapor, Surface Fluxes, and Radiation, J. Climate, 25, 6885-6904, https://doi.org/10.1175/JCLI-D-11-00258.1, 2012.

Tompkins, A. M. and Semie, A. G.: Organization of tropical convection in low vertical wind shears: Role of updraft entrainment, J. Adv. Model. Earth Sy., 9, 1046-1068, https://doi.org/10.1002/2016MS000802, 2017.

Twomey, S.: The Influence of Pollution on the Shortwave Albedo of Clouds, J. Atmos. Sci., 34, 1149-1152, https://doi.org/10.1175/15200469(1977)034<1149:TIOPOT>2.0.CO;2, 1977.

Vial, J., Vogel, R., Bony, S., Stevens, B., Winker, D. M., Cai, X., Hohenegger, C., Naumann, A. K., and Brogniez, H.: A New Look at the Daily Cycle of Trade Wind Cumuli, J. Adv. Model. Earth Sy., 11, 3148-3166, https://doi.org/10.1029/2019MS001746, 2019.

Walther, A., Straka, W., and Heidinger, A. K.: Algorithm Theoretical Basis Document: Daytime Cloud Optical and Microphysical Properties (DCOMP), Version 3.0, NOAA NESDIS Center for Satellite Applications and Research, College Park, MD, USA, https://www.star.nesdis.noaa.gov/goesr/documents/ATBDs/ Baseline/ATBD_GOES-R_Cloud_DCOMP_v3.0_Jun2013.pdf (last access: 26 January 2022), 2013.
Weger, R. C., Lee, J., Zhu, T., and Welch, R. M.: Clustering, randomness and regularity in cloud fields: 1 . Theoretical considerations, J. Geophys. Res.-Atmos., 97, 20519-20536, https://doi.org/10.1029/92JD02038, 1992.

Werner, F., Ditas, F., Siebert, H., Simmel, M., Wehner, B., Pilewskie, P., Schmeissner, T., Shaw, R. A., Hartmann, S., Wex, H., Roberts, G. C., and Wendisch, M.: Twomey effect observed from collocated microphysical and remote sensing measurements over shallow cumulus, J. Geophys. Res.-Atmos., 119, 1534-1545, https://doi.org/10.1002/2013JD020131, 2014.

Wood, R. and Hartmann, D. L.: Spatial Variability of Liquid Water Path in Marine Low Cloud: The Importance of Mesoscale Cellular Convection, J. Climate, 19, 1748-1764, https://doi.org/10.1175/JCLI3702.1, 2006.

Zhang, F., Liang, X.-Z., Zeng, Q., Gu, Y., and Su, S.: CloudAerosol-Radiation (CAR) ensemble modeling system: Overall accuracy and efficiency, Adv. Atmos. Sci., 30, 955-973, https://doi.org/10.1007/s00376-012-2171-z, 2013.

Zhao, G. and Di Girolamo, L.: Statistics on the macrophysical properties of trade wind cumuli over the tropical western Atlantic, J. Geophys. Res.-Atmos., 112, D10204, https://doi.org/10.1029/2006JD007371, 2007. 